\title{
La administración real y la movilización de los recursos de la monarquía: la Junta de Coroneles (|635-|64|)
}

\author{
Royal Administration and Mobilization of the Monarchy's \\ Resources: The Junta de Coroneles (|635-/64/)
}

\author{
AgUSTÍN JiMÉNEZ MORENO \\ IES San Fernando \\ Autovía de Colmenar Viejo km. 13500 \\ 28049 Madrid (España) \\ bazan157|@gmail.com
}

(iD

RECIBIDO: FEBRERO DE 202

ACEPTADO: MARZO DE 2021

Resumen: Desde el fin de la guerra de Mantua (|628-|63|), y sobre todo tras la ruptura de las hostilidades con Francia (1635), las necesidades militares de la monarquía española crecieron hasta niveles nunca vistos. Como consecuencia, y ante la imposibilidad de satisfacerlas por los sistemas tradicionales de reclutamiento, la administración real volvió la vista hacia los particulares, quienes podían dar respuesta, o al menos paliarlas. Pese a que el reclutamiento de nuevos contingentes era competencia de Consejo de Guerra, Olivares optó por gestionarla mediante uno de sus métodos favoritos: la constitución de una junta compuesta por hombres de confianza. Con esa finalidad surgió una entidad administrativa conocida como Junta de Coroneles, que en los años finales de la década de los 30 jugó un activo papel a la hora de aprestar hombres, sobre todo para los teatros de operaciones europeos.

Palabras clave: Siglo XVII. Conde duque de Olivares. Reclutamiento. Venalidad. Servicio militar.

Abstract: Since the end of the Mantuan War (1628-1631), and particularly after the outbreak of the war with France (1635), the military needs of the Spanish monarchy grew to levels that have never seen before. Consequently, and not being able to satisfy them by the traditional recruitment systems, the royal administration turned its attention to private contractors, who could solve or at least alleviate them. Although the recruitment of new troops was controlled by the Council of War, Olivares chose to manage it through one of his favourite methods: the formation of a "junta" composed of men of his trust. With that motivation, an administrative entity known as the "Junta de Coroneles" emerged, which played an active role in the last years of the 30s, in everything related to the sending of soldiers, specially to Flanders and Italy.

Keywords: $17^{\text {th }}$ Century. Count Duke of Olivares. Military recruitment. Venality. Military service. 


\section{AGUSTÍN JIMÉNEZ MORENO}

\section{INTRODUCCIÓN}

El revés sufrido en la Guerra de Sucesión de Mantua (I628-|63I) marcó un punto de inflexión en la política exterior de la monarquía española. En la clave de todo se encontraba la creciente hostilidad francesa, que desde el acceso del cardenal Richelieu a la primera línea política tuvo en mente liquidar la hegemonía de la Casa de Austria en el continente, tarea que acometió primero de manera encubierta, financiando a los enemigos de los Habsburgo - Holanda, Suecia y los protestantes alemanes-, y posteriormente, cuando esa línea de actuación había dado todos sus frutos, de forma directa, declarando la guerra a España en mayo de 1635 !.

Pero la ruptura de las hostilidades entre ambas monarquías ya empezó a plantearse poco después de la firma de los acuerdos de Cherasco (abril y junio de I63I), que pusieron fin a dicho conflicto. Así, ante la posibilidad de un inminente enfrentamiento con Francia, el conde duque de Olivares empezó a esbozar desde el año 1632 un ambicioso programa de medidas, destinadas a incrementar el tamaño de las fuerzas desplegadas en el corazón de la monarquía, tanto para hacer frente a una invasión francesa a través de la frontera pirenaica como para llevar a cabo un ataque preventivo que se adelantara a los designios galos. De la misma forma, se intentó incrementar los efectivos de las fortalezas fronterizas (presidios), así como efectuar reclutamientos para reforzar los ejércitos de Flandes y Milán².

Para acometer esta tarea, Olivares recurrió a la constitución de juntas, cada una de ellas encargada de algún aspecto concreto, formadas por un número reducido de colaboradores afines a su persona. En este sentido, como se ha referido habitualmente, Olivares no confiaba demasiado en el viejo sistema de consejos sobre el que se asentaba el gobierno de la monarquía. Esta suspicacia se debía a dos cuestiones fundamentales: una, el carácter de los consejos como núcleo de oposición olivarista, al estar compuestos en su mayor parte por miembros de la alta nobleza, celosos de sus preeminencias y privilegios; y dos, razones de índole operativo, pues según D. Gaspar se trataba de instituciones que adolecían de una exasperante lentitud, lo que se oponía frontalmente a sus proyectos, que exigían diligencia y rapidez en la toma de decisiones ${ }^{3}$.

\footnotetext{
I Stradling, 1986; Parrott, 1987; Elliott, 1990, pp. 258-260, 476-477, 532-547; Stradling, 1990; Jover Zamora, 2003; Negredo del Cerro, 2016, pp. I44-145, 149-150, 167-168, 208-2I7.

2 Papel que dio el conde duque al rey nuestro señor sobre las prevenciones que se debían hacer en toda la monarquía para su defensa el año de 1634, Elliott, De la Peña y Negredo del Cerro, 2013, pp. 302-3 I4.

${ }^{3}$ Elliott, 1990, pp. 165-174, 712-713; Baltar Rodríguez, 1998, pp. 74-82, 620-621, 633-635; Gil Martínez, 2015, Pp. 64-65, 72-75.
} 


\section{LA ADMINISTRACIÓN REAL Y LA MOVILIZACIÓN DE LOS RECURSOS}

\section{CONSTITUCIÓN DE LA JUNTA DE CORONELES Y PRIMERAS ACTUACIONES}

Es muy probable que los orígenes de la Junta de Coronelías -y posteriormente Junta de Coroneles, por lo que me referiré a ellas indistintamente- se encontraran en un organismo denominado Junta de Levas, activo a finales de $1633^{4}$, que se encargó de coordinar un reclutamiento encargado a una serie de grandes y títulos, cuyo objetivo era aprestar el mayor número posible de infantería para incrementar el contingente que, al frente del Cardenal Infante, partiría desde Milán con destino a Bruselas ${ }^{5}$, donde el hermano del rey asumiría el gobierno de los Países Bajos - vacante tras el fallecimiento de la infanta Isabel Clara Eugenia a principios de diciembre de dicho año-. No ha sido demasiada la información que he podido encontrar sobre ella, únicamente que continuaba en activo a principios del año 1634, cuando se ocupó de centralizar otro servicio encomendado a la nobleza para remitir 2000 hombres al presidio de Fuenterrabía, que fueron enviados a Flandes - I500 por cuenta de D. Francisco López de Zúñiga, séptimo duque de Béjar, correspondientes a los que no había entregado para el contingente de D. Fernando; 300 levados por D. Bernardino Fernández de Velasco y Tovar, sexto duque de Frías y duodécimo condestable de Castilla; y los 200 restantes por cuenta de D. Juan Ramírez de Arellano, octavo conde de Aguilar y segundo marqués consorte de la Hinojosa-; y que Juan Bautista Sáenz de Navarrete ejercía la función de secretario6.

No he podido averiguar el vínculo exacto entre la Junta de Levas y la Junta de Coronelías, pero que hay una conexión entre ambas es evidente, pues como podrá comprobarse en las páginas siguientes, uno de los principales cometidos de esta última, hasta el punto de monopolizar toda su actividad desde prácticamente principios del año 1636, fue la gestión de los reclutamientos pactados entre la Corona y aquellos particulares interesados en aprestar hombres para los reales ejércitos ${ }^{7}$. El gran perjudicado de todo ello fue el Consejo de Guerra, quien

${ }^{4}$ Consulta del Consejo de Guerra, Madrid, 26-12-1633, Archivo General de Simancas [AGS], Guerra y Marina [GYM], legajo (en adelante leg.) 1076. Consulta del Consejo de Guerra, Madrid, 23-2-I634, AGS, GYM, leg. 1095.

${ }^{5}$ Se trató de un reclutamiento cuyas primeras noticias datan del mes de noviembre de 1632 , y que ha sido confundido con la formación de los regimientos nobiliarios o coronelías. A grandes rasgos, la Corona encargó a seis de los principales aristócratas: los duques de Arcos, Béjar, Medina Sidonia, Osuna, Cardona y al marqués de Priego, el levantamiento de 4000 hombres a cada uno — repartidos en 16 compañías de 250 hombres cada una-, por lo que se esperaba reunir un ejército de 24000 hombres. Sin embargo, ni de lejos se alcanzó esa cifra, que en el mejor de los casos rondó las 14000 unidades. Jiménez Moreno, 2018, pp. 88-90.

${ }^{6}$ Carta del rey al duque de Béjar, Madrid, I8-I-1634, Archivo Histórico de la Nobleza (AHNOB), Osuna, 3620/46. Consulta de la Cámara, Madrid, 22-I-1634, Archivo Histórico Nacional (AHN), Consejos, leg. 4426/15. Consulta del Consejo de Guerra. Madrid, 30-I-1634. AGS, GYM, leg. 1095.

${ }^{7}$ Los años comprendidos entre 1634-1643 fueron testigo de un auge sin precedentes del reclutamiento privado, en gran medida motivado por el incremento de las exigencias militares. A este respecto destacan las pioneras aportaciones de Thompson, |98I, si bien centradas en los reinados de Felipe II y Felipe III, continuadas por 


\section{AGUSTÍN JIMÉNEZ MORENO}

perdió la mayor parte de sus competencias en materia reclutadora y, pese a mantener su posición como principal organismo en materia defensiva, su papel se vio reducido a un segundo plano ${ }^{8}$.

Tal y como apuntan Elliott y Baltar Rodríguez, la Junta de Coronelías fue una de las 14 corporaciones subordinadas a la Junta de Ejecución de las Prevenciones de la Defensa ${ }^{9}$, creada a mediados de 1634 con la misión de disponer todo lo necesario y acelerar los preparativos para afrontar un conflicto con Francia, y que sobrevivió hasta su desaparición en 1637, cuando fue sustituida por la Junta de Ejecución, mucho más reducida, presidida por el propio Olivares ${ }^{10}$. Las primeras noticias sobre su actividad proceden de noviembre de 1634", cuando se le encomendó la formación de los regimientos nobiliarios o coronelías, encargados a algunos de los principales linajes de la Corona ${ }^{12}$.

Como no podía ser de otra manera, los integrantes de esta nueva junta pertenecían al círculo de colaboradores de Olivares. La presidencia recayó en D. Fernando de Valdés y Llano, arzobispo de Granada y presidente del Consejo de Castilla ${ }^{13}$.

Andújar Castillo, 2004, aunque sobre el ejército del siglo XVIII. No obstante, en los últimos años han sido testigo de una ingente producción historiográfica sobre esta materia, que puede apreciarse en los siguientes trabajos: Mackay, 1999, pp. I I5-I49; Andújar Castillo, 2006; Rodríguez Hernández, 2006; Rodríguez Hernández, 2007a; Jiménez Moreno, 2009; Rodríguez Hernández, 20I I; Jiménez Moreno, 20I I, PP. 422-474; Jiménez Estrella, 20II, 2012a; Parrott, 2012, pp. 10I-259; Jiménez Moreno, 2015; Jiménez Estrella, 20I7; Jiménez Moreno, 2017b.

${ }^{8}$ Sobre este organismo Domínguez Nafría, 2001, sobre todo pp. 121-147.

9 Sánchez González, 1996; Baltar Rodríguez, 1998, pp. 365-376; Jiménez Moreno, 2018. p. 47I.

10 Elliott, 1990, pp. 563-564; Baltar Rodríguez, 1998, pp. 563-564.

1 Según Baltar Rodríguez, 1998, p. 383 fue creada a propuesta de la Junta de Ejecución de las Prevenciones de la Defensa, tras una consulta fechada a mediados de diciembre (en concreto el día 14), produciéndose su constitución dos días más tarde. No obstante, la primera referencia que he encontrado sobre la Junta de las Coronelías, data de finales del mes de noviembre de 1634, cuando el secretario de este organismo, Juan Lorenzo de Villanueva, elevó una consulta al monarca, relativa a la entrega de las patentes de coronel a los aristócratas a quienes se había concedido esa distinción. Consulta de Juan Lorenzo de Villanueva, secretario de la Junta de las Coronelías, Madrid, 24-I I-I634, AGS, GYM, leg. II 25.

12 Jiménez Moreno, 2018, pp. II8-I58, I7I-205 y 249-257.

13 Nació en Cangas de Tineo (Asturias) en julio de 1575. En torno a 1595 comenzó sus estudios de Derecho Canónico en la Universidad de Salamanca, que concluyó en 1611 -previamente, en 1608, fue designado oficial de la Inquisición-. Antes de la conclusión de ese año fue nombrado inquisidor de Barcelona y se ordenó sacerdote. En 1613 pasó a desempeñar ese cometido en Zaragoza y en I623 en Toledo. En I625 fue nombrado obispo de la ciudad de Teruel, responsabilidad que ostentó hasta diciembre de 1631, cuando fue designado para hacerse cargo del obispado de León, lo que le llevó a abandonar su puesto y dirigirse a Madrid hasta el momento de tomar posesión de su nuevo destino. Sin embargo, no llegó a hacerlo, pues en abril de 1633 se le nombró arzobispo de Granada y, además, pasó a servir la presidencia del Consejo de Castilla, sustituyendo a Miguel Santos, al tiempo que asumió la presidencia de la Junta de Ejecución de las Prevenciones de la Defensa y de la Junta de Coronelías. Falleció en Madrid a finales de diciembre de I639. Escudero, 201I, p. 124; Elliott, De la Peña y Negredo, 20I3, p. 103; Gil Martínez, 2015, pp. 77-80, 86. 


\section{LA ADMINISTRACIÓN REAL Y LA MOVILIZACIÓN DE LOS RECURSOS}

Al tiempo formaron parte de ella: Fernando Ramírez Fariñas ${ }^{14}$, D. Antonio de Contreras ${ }^{15}$ y D. Jerónimo de Villanueva ${ }^{16}$. El puesto de secretario recayó inicialmente en Pedro Valle de la Cerda ${ }^{17}$, si bien unas semanas más tarde sustituido por Juan Lorenzo de Villanueva ${ }^{18}$, quien a su vez ocupó esa responsabilidad hasta finales de septiembre de 1637 , cuando debido a sus problemas de salud

${ }^{14}$ Natural de Salamanca. Desarrolló una prolífica carrera en la administración real, siendo designado consejero de Castilla en 1616. Desde incluso antes de que se produjera el ascenso de Olivares a la primera línea política ya era uno de sus hombres de confianza, como lo demuestra el hecho de que, en febrero de 1619 , se le encargara la detención de D. Rodrigo Calderón (conde de la Oliva y marqués de Siete Iglesias), una de las cabezas visibles de la administración lermista. En 1622 accedió al puesto de camarista de Castilla, y entre 1623 y 1626 sirvió el de asistente de Sevilla. En 1629 se le encomendó la recaudación, en el arzobispado de Toledo y la provincia de Guadalajara, de un donativo solicitado por la Corona ese mismo año. A finales de 1634 formó parte de la Junta de Coronelías, participando también en otros organismos constituidos durante esos años como la Junta de la Sal. Falleció en I638. Lanza García, 2010, p. I28; Gil Martínez, 20I5, pp. 75 y 81 .

15 Nació en Segovia en I59I. Hijo de D. Jerónimo Antonio de Contreras y Dña. María González Bernaldo de Quirós. Estudio en la Universidad de Salamanca, siendo colegial del Colegio Mayor de Oviedo. Tras licenciarse, su primer destino fue el de juez mayor de Vizcaya en la Chancillería de Valladolid (I6I7), al que le siguieron los de consejero de Hacienda (1622) y Castilla (1630) y el de camarista de Castilla (también en 1630). En 1634 ingresó en la orden de Calatrava, y a finales de ese año pasó a formar parte de la Junta de Coronelías. Falleció en Madrid en I670. AHN, Órdenes Militares [OO.MM.], Caballeros-Calatrava, Expediente 620. Fayard, 1982, p. 508; Gil Martínez, 2015, p. 81.

16 Nació en Madrid, en 1594. Hijo de Agustín de Villanueva Esteban —secretario real de posible origen converso- y de Dña. Ana Díez de Villegas. Estudió con los jesuitas y, gracias a su padre, empezó su carrera en la administración, primero en las secretarías de Aragón y Mallorca, hasta que en 1620 consiguió el puesto de protonotario de Aragón. El hecho de que su familia perteneciera al círculo clientelar de los Lerma-Uceda le colocó en una posición comprometida. Sin embargo, su destacada actuación durante las Cortes de Aragón de 1626, que coincidieron con una visita real a dicho Reino, llamó la atención de Olivares, que le reclutó para formar parte de su equipo, lo que supuso un espaldarazo a su trayectoria profesional. Ese mismo año ingresó en la orden de Calatrava, y poco después fue empleado como secretario del Despacho Universa (1627), miembro de la Junta del Almirantazgo (1629), secretario de Estado de la parte de España (1630), integrante de la Junta de Ejecución de las Prevenciones de la Defensa, así como de la Junta de Coronelías (ambas en 1634) y de la Junta de Ejecución (1637). La caída de Olivares supuso el principio del fin de su carrera, llegando a ser encarcelado por la Inquisición y privado de libertad durante dos años (I644- I646). A ser liberado abandonó la vida pública y se retiró a Zaragoza, donde murió en I653. AHN, OO.MM., Expedientillos, 9913. Elliott, 1977, pp. 228-230. Elliott, De la Peña y Negredo del Cerro, 2013, p. 109 (nota 44). Gil Martínez, 2015, pp. 78-79 y 88; Sánchez Durán, 2016, pp. 252-258 y 288-296.

17 Nació en Madrid a finales del siglo XVI. Hijo de D. Luis Valle de la Cerda, contador mayor del Consejo de Cruzada, y de Dña. Luisa de Alvarado. Otro de los principales miembros de la facción olivarista, que además era cuñado del protonotario de Aragón - por matrimonio con su hija Cecilia de Villanueva-. En I636 fue admitido en la milicia calatrava. Respecto a su trayectoria profesional, ocupó los puestos de consejero de Hacienda, Cruzada y Guerra. Falleció en 1647. AHN, OO.MM., Caballeros-Calatrava, Expediente 2704. Álvarez y Baena, Tomo IV, I79I. p. 212; Gil Martínez, 20I5, pp. 82 y 88.

18 Las referencias biográficas sobre este personaje son mucho menos abundantes que las de sus compañeros de junta. A este respecto, tal y como apunta Baltar Rodríguez, era primo de D. Jerónimo de Villanueva, y fue secretario del Consejo de Aragón, donde se encargó de la negociación de Cerdeña (1612-1619), siendo promovido a la de Cataluña, que desempeñó hasta su muerte, antes de la conclusión del año 1637. Baltar Rodríguez, 200I, p. 7I. 


\section{AGUSTÍN JIMÉNEZ MORENO}

— por culpa de los cuales fallecería poco después_, fue relevado por Pedro de Villanueva.

Al tiempo que la Junta trabajaba en la puesta en marcha de las coronelías, comenzó a asumir otro cometido que poco a poco superó al primero y se convirtió en su principal razón de ser hasta su desaparición: gestionar los reclutamientos efectuados por particulares, asumiendo la responsabilidad de que los concluyeran con éxito. Pero no solo se encargó de acordar levas privadas, sino que también se le encomendó la tarea de aprestar los hombres pedidos a los corregidores, y más adelante la de reclutar hombres con sus propios medios - procedentes de una serie de expedientes puestos a su disposición por la Corona-.

La primera noticia de participación de la Junta de Coronelías en un reclutamiento de esta naturaleza se produjo a finales de octubre de 1635. No obstante, dicha intervención tuvo lugar de una manera secundaria y para complementar un reclutamiento encargado en el mes de julio a D. Pedro Álvarez de Toledo y Leyva, marqués de Mancera, gobernador y capitán general del reino de Galicia, consistente en la entrega de 1200 hombres en La Coruña para embarcarse con destino a Flandes ${ }^{19}$, que sería ejecutado por algunos de los principales miembros de la nobleza autóctona ${ }^{20}$.

Ante las enormes dificultades que estaba encontrando el marqués de Mancera para cumplir con su tarea, la administración real optó por involucrar en ella a la Junta de Coronelías, con la esperanza de que realizara una cuantiosa aportación que incrementara los efectivos que se pretendía remitir al teatro de operaciones septentrional. En un primer momento se pensó encargarla del reclutamiento de 2000 hombres, distribuidos de la siguiente manera: I I 00 correspondientes a un servicio que debían cumplir los corregidores de las ciudades castellanas; 500 por cuenta del duque de Béjar, y otros 400 por la de D. Luis Fernández de Córdoba y Aragón, cuarto marqués consorte de Poza ${ }^{21}$ - si bien poco después, al pactar con la Junta la conmutación de esos hombres por un pago en

\footnotetext{
${ }^{19}$ Desde la firma del Tratado de Madrid (noviembre de 1630), que puso fin al conflicto que enfrentaba a España e Inglaterra desde 1625, la ruta marítima hacia los Países Bajos volvió a plantearse con una opción a tener en cuenta para enviar fondos y refuerzos al ejército de Flandes, máxime cuando en agosto de 1634 ambas potencias suscribieron un tratado naval. Taylor, 1972, pp. 240-248; Alcalá-Zamora y Queipo de Llano, 1975, Pp. 344-358; Sanz Camañes, 2002, pp. 92-I35.

20 Se trataba de los condes de Altamira (400 hombres), Lemos (300), Monterrey (300) y Rivadavia (200). Jiménez Moreno, 2015, pp. 63-65. Sobre la importancia de este puerto como punto de partida de diferentes expediciones con destino a los Países Bajos durante esos años Saavedra Vázquez, 1996, Pp. 143-I75; Rodríguez Hernández, 2007b, pp. 214-218 y 238-24I.

${ }^{21}$ Relación del estado que hoy tiene lo que se ha obrado por la Junta de las Coronelías de la posada del señor arzobispo de Granada hasta 21 de octubre de 1635, Sin lugar (en adelante s.l.), sin fecha (en adelante s.f.), AGS, GYM, leg. I I 2 I. Jiménez Moreno, 2015, pp. 69-70.
} 


\section{LA ADMINISTRACIÓN REAL Y LA MOVILIZACIÓN DE LOS RECURSOS}

metálico, su contribución se vio incrementada hasta el medio millar de soldados, cuyo reclutamiento fue realizado por el marqués de la Hinojosa ${ }^{22}$ - A ellos se unieron poco después $\mathrm{D}$. Álvaro Pérez Osorio, noveno marqués de Astorga, quien se comprometió a entregar 400 unidades más ${ }^{23}$; y D. Juan Alfonso Pimentel de León, séptimo duque y décimo conde de Benavente, con quien se pactó el envío de otras 400; de manera que el total ascendió a 2900 hombres ${ }^{24}$.

Respecto a la decisión de recurrir a la Junta de Coronelías para esa tarea, me inclino a pensar que tendría que ver con el trabajo que durante los meses anteriores desempeñó en la formación de los regimientos nobiliarios. En este sentido, las negociaciones con los aristócratas adscritos a esa iniciativa permitieron a la Junta adquirir una considerable experiencia a la hora de abordar la ardua tarea de reunir hombres para los reales ejércitos. De la misma forma, cabe la posibilidad de que en el desempeño de su cometido fuera conformando un entramado de lealtades y contactos, muy valiosos para concluir con éxito su misión; sirviendo como intermediarios entre los particulares interesados y la Corona. Pero la idoneidad de la Junta para esta tarea no habría servido de mucho si no hubiera contado con una poderosa herramienta: las patentes de capitán en blanco ${ }^{25}$. En cuanto a este particular, la administración real puso en sus manos un elevado número de ellas - normalmente una por cada 100 hombres-; aunque también autorizó las emisiones de deuda poniendo como garantía los bienes amayorazgados -imponer o tomar a censo en la terminología de la época- ${ }^{26}$, o la entrega de mercedes de hábito a los reclutadores, para que estos las hicieran efectivas en quien consideraran oportuno.

Durante las semanas siguientes su protagonismo aumentó todavía más, máxime cuando a principios del mes de noviembre el marqués de Mancera ordenó el embarque de los 770 hombres que hasta esos instantes había conseguido reunir -350 del conde de Altamira, 220 el conde de Monterrey y 200 el de Lemos-, organizados en cuatro compañías que se embarcaron en la armada al

22 Esta fue la primera de una serie de levas que la Junta de Coronelías encargó a D. Juan Ramírez de Arellano, octavo conde de Aguilar y segundo marqués consorte de la Hinojosa, comenzando una fructífera colaboración entre ambas, que llevó a este aristócrata a convertirse en el principal reclutador privado durante los años finales del ministerio de Olivares. Memorial de D. Juan Ramírez de Mendoza y Arellano, marqués de La Hinojosa, conde de Aguilar, s.I., s.f., AGS, GYM, leg. 1255.

${ }^{23}$ Carta del marqués de Astorga al secretario D. Fernando Ruiz de Contreras, Astorga, 30-10-1635, AGS, GYM, leg. 1124.

${ }^{24}$ Relación del estado que hoy tiene lo que se ha obrado por la Junta de las Coronelías de la posada del señor arzobispo de Granada hasta 21 de octubre de 1635, s.I., s.f., AGS, GYM, leg. I I 2 I. Carta del marqués de Astorga al secretario D. Fernando Ruiz de Contreras, Astorga, 30-10-1635, AGS, GYM, leg. I I24. Papel del secretario Juan Lorenzo de Villanueva al secretario D. Fernando Ruiz de Contreras. Madrid, I2-12-1635. AHN, Estado, leg. 6405(2), núm. 62.

25 Rodríguez Hernández, 2007a; Jiménez Estrella, 20I I.

26 Sobre esta materia Jago, 1973 y 1979; Yun Casalilla, 1990. 


\section{AGUSTÍN JIMÉNEZ MORENO}

mando del general Masibradi ${ }^{27}$. La razón que adujo para ello fue la poca confianza que tenía en incrementar ese número, considerando imposible llegar a los 1200 efectivos que se le habían encargado. De este modo, y ante la posibilidad de que los soldados pudieran perderse como consecuencia de las deserciones, tomó esa decisión ${ }^{28}$.

En cuanto a los resultados prácticos de esta primera experiencia, a principios de abril de 1636 ya habían llegado a La Coruña 1674 hombres procedentes de los reclutamientos gestionados por la Junta de Coronelías ${ }^{29}$, y poco después llegaron otros 745 correspondientes a la contribución del duque de Béjar ${ }^{30}$. Mientras tanto, durante los meses siguientes empezaron a confluir en Galicia los navíos que se encargarían de transportar los hombres. No obstante, hasta mediados de agosto de dicho año no se produjo la partida de esta fuerza naval, compuesta por 26 navíos, cuyo mando recayó en D. Juan Claros de Guzmán, segundo marqués de Fuentes ${ }^{31}$ - hermano del duque de Medina Sidonia y máximo responsable de la Armada de Flandes, como almirante general, desde principios de 1634-. El número final de efectivos que se embarcaron fue de 3774 infantes $^{32}$, lo que supone unos 874 más de los planteados en un primer momento. Este incremento puede deberse a que la Junta de Coronelías consiguió que los reclutadores aumentaran sus cuotas, o porque pactara la entrega de más hombres con nuevos reclutadores. Aunque también podría corresponder a servicios gestionados con otras entidades administrativas, sin descartar que parte de ellos fueran soldados que servían en los presidios, los cuales fueron incluidos en el contingente que se enviaría a Flandes; o incluso una combinación de las tres posibilidades.

\footnotetext{
${ }^{27}$ Jerónimo Masibradi era un marino natural de Ragusa, que en 1624 entró al servicio de Felipe IV, con quien suscribió un asiento para servir a la monarquía española con su escuadra de seis galeones, los cuales fueron adscritos a la Armada del Mar Océano. Goodman, 200 I, pp. 295-296.

${ }^{28}$ Carta del marqués de Mancera al secretario D. Fernando Ruiz de Contreras, La Coruña, II-II-1635, AGS, GYM, leg. II 24.

${ }^{29}$ Consulta de la Junta de las Coronelías, Madrid, 2I-4-1636, AGS, GYM, leg. I 186.

${ }^{30}$ Certificación de Diego Portillo de la infantería que se recibió al sueldo de la leva del señor duque de Béjar, La Coruña, 27-4-1636, AHNOB, Osuna, 242, fol. $21 \mathrm{r}$.

${ }^{31}$ Alcalá-Zamora y Queipo de Llano, 1975, pp. 375-390; Stradling, 1992, pp. 134-136; Vermeir, 2006, pp. I76, 200 y 346.

${ }^{32}$ Consulta de la Junta de Armadas, Madrid, 28-8-1636, AGS, GYM, leg. 3167.
} 


\section{LA ADMINISTRACIÓN REAL Y LA MOVILIZACIÓN DE LOS RECURSOS}

\section{LA ÉPOCA DE ESPLENDOR DE LA JUNTA DE CORONELES}

\section{I. Reclutamiento para los Países Bajos (I 636-I 637)}

Unos días después de que el marqués de Fuentes llegara felizmente a Flandes, acontecimiento que tuvo lugar a principios de septiembre, y en vista del éxito obtenido, se decidió preparar una nueva expedición. La primera noticia sobre ella data de mediados de dicho mes, y se enmarca en las disposiciones a adoptar para la campaña del año I637. En este sentido, la Junta de Ejecución del Ejército ${ }^{33}$ planteó a Felipe IV la conveniencia de enviar nuevos refuerzos al teatro de operaciones septentrional. Sus planes contemplaban reunir unos 2000-3000 hombres, que al igual que en el caso anterior se reunirían en Galicia para embarcarse con destino a los Países Bajos ${ }^{34}$, recayendo la responsabilidad de llevar a cabo los reclutamientos en la Junta de Coroneles, aunque también debía hacerse cargo de la paga y manutención de los hombres, una vez fueran entregados a los oficiales reales. En esta ocasión se contemplaba la realización de una serie de levas en el área andaluza, que se embarcarían en el puerto de Cádiz para viajar a La Coruña y desde allí, tras hacer lo propio los efectivos que debían reunirse en Galicia, viajar juntos hacia Flandes ${ }^{35}$.

Pero durante las semanas siguientes, tal y como se aprecia en el Cuadro I, se perfilaron las condiciones definitivas de esta asistencia, hasta el punto de alcanzarse entre todas las aportaciones unos efectivos teóricos de 7300 hombres —4300 en La Coruña y 3000 en Cádiz-, si bien se trataba de unas pretensiones que pecaban de un exceso de optimismo.

\footnotetext{
${ }^{33}$ Se trata de otra de las juntas que asumió competencias militares, entre las que se incluía el reclutamiento de efectivos para el ejército. Se encontraba operativa en el mes de marzo de 1635, por lo que es probable que dependiera de la Junta de la Ejecución de las Prevenciones de la Defensa. Respecto a sus miembros, estaba compuesta por el propio Olivares, el marqués de Santa Cruz, D. Carlos Coloma, el duque de Villahermosa el marqués de Castrofuerte, D. Jerónimo de Villanueva y Pedro de Arce. Entre sus competencias se encontraba todo lo relativo a la dinamización de los preparativos militares, y más concretamente el envío de las tropas a los distintos teatros de operaciones en los que combatían las tropas de la monarquía española. En abril de 1638 aún se encontraba en activo, por lo que debió desaparecer a finales de 1638 o principios de 1639, integrándose en la Junta de Ejecución. Sánchez González, 1996, Pp. 137-146; Baltar Rodríguez, 1998, pp. 394-397; Jiménez Moreno, 2018, pp. 47I-472.

34 Consulta de la Junta de la Ejecución del Ejército, Madrid, I5-9-1636, AGS, GYM, leg. II54.

${ }^{35}$ Consulta de la Junta de la Ejecución del Ejército, Madrid, I6-9-1636, AGS, GYM, leg. II 54.
} 


\section{AGUSTÍN JIMÉNEZ MORENO}

Cuadro I. Proyecto encargado a la Junta de Coroneles para reclutar infantería con destino al ejército de Flandes (septiembre, 1636). Fuente: AGS, GYM, legs. II5I, II54, II85, I26I, I3II, 3168.

\begin{tabular}{l|r|r|r|r}
\hline & Hombres pedidos & \multicolumn{1}{|c|}{$\begin{array}{c}\text { Hombres } \\
\text { entregados }\end{array}$} & \multicolumn{1}{c|}{$\begin{array}{c}\text { Puerto de } \\
\text { embarque }\end{array}$} & $\begin{array}{r}\text { Porcentaje de } \\
\text { cumplimiento }\end{array}$ \\
\hline Arzobispo de Burgos' & 300 & $0^{2}$ & La Coruña & $0 \%$ \\
\hline Arzobispo de México & 300 & $0^{4}$ & Cádiz & $0 \%$ \\
\hline Arzobispo de Santiago & 0 & La Coruña & $73 \%$ \\
\hline $\begin{array}{l}\text { Capitán Pedro de los } \\
\text { Reyes }\end{array}$ & 100 & 73 & La Coruña & $125 \%$ \\
\hline Conde de Altamira & 300 & 374 & La Coruña & $0 \%$ \\
\hline Conde de Medellín & 200 & 0 & La Coruña & $0 \%$ \\
\hline Conde de Miranda & 300 & 0 & La Coruña & $0 \%$ \\
\hline Conde de Osorno & 350 & 0 & La Coruña & 112 \\
\hline Condestable de Castilla & 1000 & 1121 & La Coruña & $86 \%$ \\
\hline $\begin{array}{l}\text { Corregidores de } \\
\text { Andalucía }\end{array}$ & 1500 & 1286 & Cádiz & $80 \%$ \\
\hline $\begin{array}{l}\text { Corregidores de Castilla } \\
\text { la Vieja }\end{array}$ & 1350 & 1084 & La Coruña & $0 \%$ \\
\hline Marqués de Cerralbo & 500 & 0 & Cádiz & $52 \%$ \\
\hline Marqués de Estepa & 300 & 157 & Cádiz & $8 \%$ \\
\hline Marqués de la Algaba & $\mathbf{4 3 0 0}$ & $\mathbf{3 1}$ & Cádiz & $\mathbf{5 6 , 5 \%}$ \\
\hline
\end{tabular}

'El titular de ese arzobispado era D. Fernando de Andrade y Sotomayor, que ostentó el cargo entre I6311640. Datos biográficos en: http://dbe.rah.es/biografias/42187/fernando-de-andrade-y-sotomayor (Consultado 22-12-2019).

2 En lugar de los hombres que se le pidieron contribuyó con 22000 reales, que fueron empleados en financiar el contingente que debía entregar el corregidor de Burgos. Relación de lo que se debe por el gasto que han hecho algunos corregidores en las levas viejas, y sacado a pagar a la Junta de Coroneles, para que por ella se pague y restituya a donde se tomó. S.I., s.f. (1639). AGS, GYM, Leg. I26I.

${ }^{3}$ Se trababa de D. Francisco Manso de Zúñiga, que había ocupado ese puesto hasta 1635. A mediados de 1636 se encontraba en España y poco después (en 1637) fue promovido al puesto de obispo de Cartagena, para finalizar su carrera en el arzobispado de Burgos. http://dbe.rah.es/biografias/50442/francisco-manso-de-zuniga (Consultado 22-12-2019).

${ }^{4}$ A cambio sirvió con un cuantioso donativo, equivalente a 10000 pesos en plata (3000 entregados en esos instantes y los 7000 restantes en México). Relación del estado que tienen las levas que corren por la Junta de Coroneles. S.I., s.f. (principios julio I637). AGS, GYM, Leg. 3168.

${ }^{5}$ El puesto se encontraba en manos de D. Agustín Spínola y Basadone, hijo segundo de D. Ambrosio Spínola, primer marqués de los Balbases, que lo desempeñó entre 1630 y 1645, cuando fue promovido al arzobispado de Sevilla. http://dbe.rah.es/biografias/21 I24/agustin-spinola (Consultado 22-12-2019).

${ }^{6}$ Los incluidos eran los de las siguientes ciudades: Antequera, Baeza, Carmona, Écija, Granada, Guadix, Jaén, Málaga, Ronda y Sevilla.

Hasta finales del mes de junio de 1637 habían llegado a Cádiz I474 soldados - casi la mitad de los que deberían haberlo hecho-, correspondientes en su mayor parte a la cuota que debían entregar los corregidores; mientras que en La Coruña únicamente se encontraban 874 unidades (el 20,32\%). De manera que sumando ambas aportaciones, en esos instantes se había alcanzado poco menos de la tercera parte de los hombres que se pretendía levantar (el 32, I6\%). Durante los meses siguientes continuaron llegando más hombres, aunque en ningún caso se alcanzarían los 7300 proyectados. A principios del mes de diciembre, cuando 


\section{LA ADMINISTRACIÓN REAL Y LA MOVILIZACIÓN DE LOS RECURSOS}

se produjo la partida de la armada al mando del general D. Lope de Hoces ${ }^{36}$, que llegó al puerto de Dunquerque unos días más tarde ${ }^{37}$, la Junta de Coronelías había sido capaz de entregar 4126 hombres, lo que suponía algo más del $56 \%$ del objetivo inicial. A pesar de todo, se observan grandes diferencias, pues mientras que siete de ellos no entregaron ni un solo hombre - si bien los arzobispos de Burgos y México contribuyeron con una suma en metálico-, otros, como el condestable de Castilla y el conde de Altamira ${ }^{38}$, entregaron más soldados de los que tenían obligación.

La explicación más plausible a esas variaciones tendría que ver con la generosidad de la Corona, pues ambos aristócratas obtuvieron grandes beneficios a cambio de su asistencia. El principal incentivo del condestable de Castilla para involucrarse en este proyecto fue garantizar la cobranza de las alcabalas de Arnedo (La Rioja), que la Real Hacienda estaba dispuesta a recuperar por la vía judicial si no realizaba una cuantiosa contribución - al menos un millar de efectivos- ${ }^{39}$. No obstante, para que pudiera cumplir con este encargo más fácilmente se le despacharon 10 patentes de capitán en blanco con los correspondientes suplimientos ${ }^{40}$, y recibió permiso para endeudarse en 20000 ducados, poniendo como garantía sus bienes amayorazgados ${ }^{41}$.

En el caso del conde de Altamira, recibió mercedes de muy diversa naturaleza, que se tradujeron en una mejora de su situación económica. En primer lugar, se incrementó en dos años más - que unos meses más tarde se vieron aumentados a 12- el plazo que se había concedido a su padre para amortizar los censos que gravaban su mayorazgo; $y$, poco después, recibió permiso para sacar de sus tierras en el reino de Galicia, e introducir en Castilla, 6000 fanegas de cereales - 2000 de trigo, 2000 de centeno y otras tantas de mijo y maíz-, si bien abonando las cantidades correspondientes al derecho de la media anata ${ }^{42}$.

${ }^{36}$ Sobre este magnífico marino véase: http://dbe.rah.es/biografias/26461/lope-de-hoces-y-cordoba (Consultado 22-12-2019).

${ }^{37}$ Consulta de la Junta de Armadas, Madrid, 17-12-1637, AGS, GYM, leg. 3168. Carta de D. Lope de Hoces y Córdoba al rey refiriendo su llegada a Flandes, Dunquerque, 20-12-1637, AGS, GYM, leg. 1214.

${ }^{38}$ D. Gaspar de Moscoso Osorio y Sandoval, sexto conde de Altamira, que acababa de suceder a su padre, D. Lope de Moscoso Osorio y Castro, quinto conde de Altamira, fallecido en septiembre de 1636. http://dbe.rah.es/biografias/71621/lope-de-moscoso-osorio-y-castro (Consultado 22-12-2019).

39 Domínguez Ortiz, 1973, pp. $94-95$ (nota 18).

40 Papel del secretario Juan Lorenzo de Villanueva al secretario D. Fernando Ruiz de Contreras, Madrid, 18-10-1636, AGS, GYM, leg. II 85.

${ }^{41}$ Papel del secretario Juan Lorenzo de Villanueva al secretario D. Antonio de Alosa, Madrid, 6-I I-1636, AHN, Estado, leg. 6405(2), núm. 6I. Real Cédula concediendo facultad a D. Bernardino Fernández de Velasco, condestable de Castilla, para imponer censos sobre su casa, estado y mayorazgo por 20000 ducados de principal para los gastos de la leva de los 1000 infantes con que sirve, Madrid, 9-12-1636, AHNOB, Frías, 274/I7.

${ }^{42}$ Carta del secretario Juan Lorenzo de Villanueva al secretario D. Antonio de Alosa, Madrid, 7-I2-1636, AHN, Estado, leg. 6405(2). 


\section{AGUSTÍN JIMÉNEZ MORENO}

También se le permitió imponer nuevos títulos de deuda por un importe máximo de 24000 ducados, y recibió tres patentes de capitán en blanco con suplimien$\operatorname{tos}^{43}$.

En el caso de las ciudades de Castilla, también se aprecian grandes oscilaciones. Por ejemplo, tres de ellas: las Cuatro Villas de la Costa de la Mar - jurisdicción que comprendía las ciudades de Laredo, Castro Urdiales, San Vicente de la Barquera y Santander, en la actual comunidad de Cantabria-, Toledo y Zamora consiguieron salir indemnes de este servicio. Pero eso no quería decir que no aportaran absolutamente nada, máxime cuando la administración real tenía tanta necesidad de hombres. En el caso de las Cuatro Villas es muy probable que se decidiera relevarlas de esta obligación porque en torno a abril-mayo de 1636 se ordenó que esa jurisdicción aprestara 400 marineros para servir ese año en la Armada ${ }^{44}$. Ante la coincidencia de ambas solicitudes, cabe la posibilidad de que los dirigentes de la monarquía consideraran que era más importante garantizar la dotación de los navíos, y dieran marcha atrás en su deseo de reclutar soldados allí. Mientras que, en el caso de Toledo y Zamora, la explicación más factible podría ser que se estuvieran realizando en ellas otros servicios, posiblemente para aprestar los efectivos de la milicia y/o garantizar la dotación de los presidios, lo que habría agotado momentáneamente su capacidad reclutadora, algo relativamente habitual en esos años por la coexistencia de varios servicios.

Por el contrario, cinco de ellas fueron capaces de entregar más hombres de los pedidos inicialmente, destacando lo acontecido en León que entregó un $184 \%$ de unidades de más, o Salamanca con el 170\%. También se aprecian porcentajes por encima de la media en los casos de Asturias, Valladolid y Toro. Es posible que la respuesta a estas fluctuaciones se encuentre en el modo en que se efectuaron los reclutamientos. Así, la Junta de Coroneles entregó las patentes de capitán a una serie de militares escogidos por ella, a cada uno de los cuales se le asignó un corregimiento para reunir los hombres que le correspondían. Es decir, los corregidores quedaron fuera del lucrativo negocio del nombramiento de la oficialidad de las compañías que se aprestaban en sus jurisdicciones. Ante esta situación no sería descabellado suponer que, pese a las instrucciones dadas por la Corona para que los corregidores prestaran toda la ayuda posible a los capitanes -ordenándoles que pusieran a su disposición todos los condenados a pena de vergüenza pública ${ }^{45}$ o destierro, con el objetivo de que fueran incluidos en las levas ${ }^{46}$-, los resultados fueran mucho menores de lo esperado. $O$, en cualquier

43 Consulta de la Junta de Coronelías, Madrid, 19-10-1637, AGS, GYM, leg. II85.

${ }^{44}$ Consulta de la Junta de Armadas, Madrid, 12-5-1636, AGS, GYM, leg. 3167.

45 Sobre este delito Ortego Gil, 1998, pp. 153-164.

${ }^{46}$ Decreto del rey dirigido al arzobispo de Granada, Madrid, I2-4-I637, AGS, GYM, leg. I I82. Carta del arzobispo de 


\section{LA ADMINISTRACIÓN REAL Y LA MOVILIZACIÓN DE LOS RECURSOS}

caso, inferiores de haber estado en su mano la designación de la persona que ostentaría el empleo de capitán.

Cuadro 2. Aportaciones de los corregidores castellanos (gestionadas por la Junta de Coroneles) entregadas en La Coruña durante el año I637. Fuente: AGS, GYM, legs. 3 I I I, 3 I 68.

\begin{tabular}{|c|c|c|c|}
\hline & $\begin{array}{l}\text { Hombres } \\
\text { pedidos }\end{array}$ & $\begin{array}{c}\text { Hombres } \\
\text { entregados }\end{array}$ & $\begin{array}{l}\text { Porcentaje de } \\
\text { cumplimiento }\end{array}$ \\
\hline Asturias & 200 & 359 & $179,5 \%$ \\
\hline Ávila & 50 & 50 & $100 \%$ \\
\hline Burgos & 150 & 98 & $65,3 \%$ \\
\hline Cuatro Villas & 300 & 0 & $0 \%$ \\
\hline León & 50 & 142 & $284 \%$ \\
\hline Palencia & 200 & 72 & $36 \%$ \\
\hline Salamanca & 50 & 135 & $270 \%$ \\
\hline Segovia & 50 & 47 & $94 \%$ \\
\hline Toledo & 100 & 0 & $0 \%$ \\
\hline Toro & 50 & 60 & $120 \%$ \\
\hline Valladolid & 100 & 121 & $121 \%$ \\
\hline \multirow[t]{2}{*}{ Zamora } & 50 & 0 & $0 \%$ \\
\hline & 1350 & 1084 & $80,29 \%$ \\
\hline
\end{tabular}

Pese al esfuerzo realizado por este organismo para reunir un contingente tan cuantioso, un importante número de hombres permanecieron en tierra. Según informó la Junta de Armadas poco después de la partida de $\mathrm{D}$. Lope de Hoces, se habían embarcado en La Coruña 4126 hombres procedentes de las levas realizadas durante los meses anteriores ${ }^{47}$. De ellos, como consta en el cuadro 3, la Junta de Coroneles aportó 2652, pero solo se embarcaron 1742, casi el 66\%; es decir, uno de cada tres soldados reclutados por intermediación de esta Junta permaneció en tierra. En cuanto a los 910 restantes, 624 (el 23,5\% del total) se encontraban enfermos; I I 3 (4\%) murieron; I 0 I desertaron (3,8\%), lo que supone una tasa de abandono del servicio excepcionalmente bajo; y los 72 restantes $(2,7 \%)$ fueron rechazados por no ser aptos para servicio.

Eso indica que los 1474 hombres restantes fueron levados por otros reclutadores. De ellos, quien presentó una aportación más cuantiosa fue el marqués

Granada a los corregidores de Castilla la Vieja y Andalucia, ordenándoles ayuden y asistan a los capitanes que están levantando gente, Madrid, I3-4-1637, AGS, GA, leg. II82.

${ }^{47}$ Según Alcalá-Zamora se embarcaron en esa escuadra como refuerzo para el ejército de Flandes 5255 plazas. A ellos sumó otros 7036 marineros y soldados que servían en esa fuerza naval, elevando la cifra final a casi 12 400. Pero según la propia Junta de Armadas, el número total de efectivos ascendió a 7033, desglosados de la siguiente forma: 4126 procedentes de las levas, II 29 soldados de infantería que prestaban servicio en los 38 navíos que integraban la armada y, finalmente, 1778 marineros. Consulta de la Junta de Armadas, Madrid, 17-12-1637, AGS, GYM, leg. 3168. Alcalá-Zamora y Queipo de Llano, 1975, p. 390. 
de Mancera, a quien de nuevo se le encargó que reuniera el mayor número posible de hombres, presentando I57I. A ellos se sumaron 455 reunidos por una serie de localidades - la mayor parte de ellas extremeñas-48; y otros 193 alistados en varias ciudades de Galicia. Las órdenes religiosas de San Benito y San Bernardo contribuyeron con 162 plazas y, finalmente, los obispos de Lugo y Orense aportaron 69 más $^{49}$. De este modo el número de hombres reclutados totalizó 5102; de los cuales se embarcaron 3604 y otros 854 permanecieron en tierra -mientras que los 644 restantes corresponden a los fallecidos, desertores y despedidos por inútiles-.

Cuadro 3. Hombres reclutados por mediación de la Junta de Coroneles durante el año 1637 entregados en La Coruña. Fuente: AGS, GYM, leg. I 3 I I.

\begin{tabular}{|c|c|c|c|c|c|c|}
\hline & Entregados & Embarcados & $\begin{array}{c}\text { En los } \\
\text { hospitales }\end{array}$ & Muertos & Despedidos & Fugados \\
\hline Asturias & 359 & 188 & 129 & 18 & 5 & 19 \\
\hline Ávila & 50 & 40 & 2 & 4 & 4 & 0 \\
\hline Burgos & 98 & 78 & I & 5 & 5 & 9 \\
\hline $\begin{array}{l}\text { Capitán } \\
\text { Pedro de } \\
\text { los Reyes }\end{array}$ & 73 & 53 & 7 & 6 & 3 & 4 \\
\hline $\begin{array}{l}\text { Conde de } \\
\text { Altamira }\end{array}$ & 374 & 230 & 100 & 17 & 6 & 21 \\
\hline $\begin{array}{l}\text { Condestable } \\
\text { de Castilla }\end{array}$ & $I I 2 I$ & 743 & 288 & 43 & 14 & 33 \\
\hline León & 142 & 100 & 26 & 2 & 6 & 8 \\
\hline Palencia & 72 & 62 & I & 4 & 5 & 0 \\
\hline Salamanca & 135 & 84 & 33 & 5 & 10 & 3 \\
\hline Segovia & 47 & 36 & 2 & 4 & 3 & 2 \\
\hline Toro & 60 & 26 & 28 & I & 3 & 2 \\
\hline \multirow[t]{2}{*}{ Valladolid } & 121 & 102 & 7 & 4 & 8 & 0 \\
\hline & 2652 & 1742 & 624 & 113 & 72 & 101 \\
\hline
\end{tabular}

Pero como ya referí con anterioridad, en los navíos al mando de D. Lope de Hoces se encontraban $4 I 26$ soldados procedentes de las levas, por lo que hay un desfase de 385 efectivos. Es posible que esos hombres correspondieran al contingente reunido por la Junta de Coroneles en el puerto de Cádiz, el cual ascendió a 1474, y que los 1089 restantes fueran destinados a Italia, la Armada o a cualquier otro destino. Aunque también pudo acontecer que esas 385 unidades

${ }^{48}$ Es probable que se tratara de soldados milicianos, aprestados en las siguientes localidades extremeñas: Alburquerque, Alcántara, Badajoz, Brozas, Burguillos, Coria, Galisteo, Gata, Granadilla, Jerez de los Caballeros, Llerena, Medellín, Mérida, Plasencia, Puebla de Alcocer, Trujillo, Valencia de Alcántara, Villanueva de la Serena, Zafra; además de Ciudad Rodrigo (en la actual provincia de Salamanca).

${ }^{49}$ Relación de la infantería que ha entrado en la ciudad de La Coruña desde 14 de febrero del año pasado de 1637 hasta el día de la fecha, La Coruña, I4-2-1638, AGS, GYM, leg. I3II. 


\section{LA ADMINISTRACIÓN REAL Y LA MOVILIZACIÓN DE LOS RECURSOS}

hubieran sido presentadas por un reclutador ajeno a este organismo, y que el cupo reunido en Cádiz fuera empleado en su totalidad para otro cometido diferente del contemplado en un principio.

\subsection{Reclutamiento para Flandes e Italia ( $1637-1638)$}

A finales de septiembre de 1637, cuando aún no se había concluido el servicio anterior, Felipe IV encargó a la Junta de Coroneles uno nuevo, consistente en la leva de 6000 hombres, que en principio debían ser voluntarios ${ }^{50}$, los cuales se emplearían en reforzar los ejércitos de Flandes y Milán ${ }^{51}$. Según lo proyectado, 2000 de ellos se reunirían en La Coruña; mientras que los 4000 restantes lo harían en la localidad tarraconense de Tortosa ${ }^{52}$.

Pese a que este organismo había cumplido con éxito los encargos de los años anteriores, empezó a vislumbrarse uno de los problemas que, a la larga, acarrearía su desaparición: la falta de dinero. Aunque en muchos casos se consiguió cargar sobre los particulares el coste de los reclutamientos, a cambio de mercedes honoríficas y empleos militares, no era suficiente para atender todos los gastos. Por ese motivo, el arzobispo de Granada solicitó que se pusieran a disposición de la Junta un centenar de licencias para introducir en los reinos peninsulares mercancías procedentes de Francia y Holanda —algo que estaba prohibido por encontrarse la monarquía española en guerra contra ellas-, las cuales serían vendidas entre la comunidad mercantil sevillana, destinándose la cantidad obtenida a financiar las levas que estaban bajo su responsabilidad ${ }^{53}$. Pero además, para garantizar que estas autorizaciones se vendieran rápidamente, solicitó que no se pusieran a disposición de ningún otro organismo, y que los interesados en adquirirlas se vieran obligados dirigirse a la Junta de Coroneles ${ }^{54}$.

Respecto a la manera en que se reunirían esos efectivos, se volvió a focalizar el esfuerzo reclutador en los tres grupos a los que se había recurrido con anterioridad -nobles, ciudades y particulares-. En cuanto a grandes y títulos el objetivo de la Junta serían aquellos que no habían contribuido en las levas anteriores $y$, además, percibían las alcabalas de determinadas localidades. Ante esta

\footnotetext{
50 Pese a todo, conforme fueron avanzando los meses y se constató la cada vez mayor dificultad para conseguir hombres por esta vía, se autorizó el reclutamiento forzoso de vagabundos y gente sin ocupación, que se encontraban sobre todo en la Corte. Consulta de la Junta de Ejecución del Ejército, Madrid, 2-6-1638, AGS, GYM, leg. 1215.

51 Decreto dirigido al arzobispo de Granada, en el que le encarga levante gente para los ejércitos de Flandes e Italia, Madrid, 20-9-1637, AGS, GYM, leg. 1185.

52 Consulta de la Junta de Coroneles, Madrid, 29-10-1637, AGS, GYM, leg. I 185.

53 Respecto a esta materia López Belinchón, 200I, pp. 1044-1050; Alloza Aparicio, 2005, pp. 259-263; Gil Martínez, 2017, pp. 86-87.

54 Consulta de la Junta de las Coronelías, 25-9-1637.
} 


\section{AGUSTÍN JIMÉNEZ MORENO}

situación, se debía tantear su predisposición a contribuir con un importante número de soldados a cambio de que la Real Hacienda hiciera la vista gorda y no iniciara un proceso legal para recuperar esos ingresos, tal y como se había hecho con el condestable de Castilla ${ }^{55}$.

Así, a finales de 1637 gracias a la mediación de D. Luis de Haro, la Junta de Coroneles alcanzó sendos acuerdos con D. Alonso Fernández de Córdoba y Figueroa, quinto marqués de Priego; y D. Rodrigo Ponce de León y Álvarez de Toledo, cuarto duque de Arcos, para que a cambio de hacerse cargo, cada uno de ellos, del reclutamiento y entrega de 1000 hombres, junto con el equivalente económico de otro millar - lo que supondría 40000 ducados en el caso de Priego y 35000 en el de Arcos, cantidades que irían a parar a la bolsa de la Junta de Coroneles para financiar sus múltiples compromisos-, pudieran seguir percibiendo las alcabalas de Montilla (Córdoba) y de Marchena (Sevilla) respectivamente ${ }^{56}$.

El segundo pilar sería el auxilio que pudieran prestar los corregidores de las principales ciudades, tanto de Castilla como de Andalucía, motivándoles con la posibilidad de renovar sus mandatos -en un principio eran designados por periodos de tres años- si tenían éxito en la tarea que ahora se les encomendaba.

Mientras que el tercero y último era el de la iniciativa privada, contactando con aquellos particulares interesados en aprestar hombres para la Corona. Desde la propia administración real se sugirió la persona del marqués de la $\mathrm{Hi}-$ nojosa, quien ya había dado muestras de su eficiencia en materia reclutadora, a quien se le podía ofrecer la grandeza de España a cambio de entregar un contingente lo más numeroso posible ${ }^{57}$. Al mismo tiempo se planteó ofrecer títulos nobiliarios, vizcondados o hábitos de las Órdenes Militares a aquellos individuos que no pertenecían al segundo estado pero que deseaban promocionar socialmente, en función de los hombres que estuvieran dispuestos a costear ${ }^{58}$.

Entre quienes se animaron a ello se encontraba D. Fernando de Meneses Pacheco y Silva, quien estaba dispuesto a ofrecer cierta cantidad de hombres reclutados a su costa a cambio de que se le ratificase el título de marqués de

55 Decreto dirigido al arzobispo de Granada, en el que le encarga levante gente para los ejércitos de Flandes e Italia, Madrid, 20-9-1637, AGS, GYM, leg. 1185.

${ }^{56}$ Consulta de la Junta de Coroneles, Madrid, I0-II-1637, AGS, GYM, leg. II82. Consulta de la Junta de Coroneles. Madrid, I8-12-1637, AGS, GYM, leg. II82. Jiménez Moreno, 20I5, Pp. 76-83.

57 Decreto dirigido al arzobispo de Granada, en el que le encarga levante gente para los ejércitos de Flandes e Italia, Madrid, 20-9-1637, AGS, GYM, leg. I 185 . Finalmente pactó con la Junta de Coroneles la entrega de 500 hombres en Cartagena, de los cuales fue capaz de presentar poco más de 300 . Sin embargo, al tiempo que se encargaba de este servicio, acordó con el Consejo de Guerra un reclutamiento más cuantioso, que ascendió a casi 1500 soldados.

${ }^{58}$ Consulta de la Junta de las Coronelías, Madrid, 25-9-I637, AGS, GYM, leg. II85. Jiménez Estrella, 20II, p. I85. 


\section{LA ADMINISTRACIÓN REAL Y LA MOVILIZACIÓN DE LOS RECURSOS}

Alconchel, al cual había accedido, en 1632, por matrimonio con una hija de la condesa de Salvatierra. Por algún motivo esta unión no fructificó, y en agosto de 1637 se dieron órdenes para anular esta merced. Para que la Corona diera marcha atrás en esa decisión, poco después - mediados del mes de octubre- pactó con la Junta de Coroneles una leva de 300 hombres -200 de ellos entregados en Perpiñán, aunque posteriormente se le indicó que lo hiciera en Tortosa-; mientras que para los 100 restantes se le planteó la opción de entregar su equivalente económico (a razón de 30 ducados por unidad), realizada en Talavera de la Reina y Cuenca. Además de la regularización de su título, se le concedieron dos patentes de capitán en blanco - entregándosele poco después otra más-, así como autorización para imponer censos sobre su mayorazgo por 12000 ducados y, finalmente, permiso para hacer efectiva la merced de hábito que se concedió a su esposa, Dña. Ana de Bois y Barbanzón, para quien contrajera matrimonio con ella, pues D. Fernando ya era caballero de Santiago (desde el año $16 / 3)^{59}$. Durante los meses siguientes envió a Tortosa 280 hombres, pero al llegar allí ningún oficial se hizo cargo de ellos, por lo que los capitanes encargados de la entrega de los hombres optaron por dirigirse a Barcelona, donde la administración virreinal sí registró su llegada, aunque con una notable disminución en el número de efectivos, pues únicamente arribaron 210 unidades —perdiéndose en el camino el $25 \%$ - ${ }^{60}$.

Junto a los nobles, otro de los perfiles más prolíficos fue el de los asentistas de soldados, algunos de los cuales pertenecían a la oficialidad del ejército, que vieron en el reclutamiento de efectivos militares una vía de promoción socioprofesional que no dudaron en aprovechar. Entre ellos se encontraba el maestre de campo D. Luis de Monsalve, quien a principios de diciembre de 1637 llegó a un acuerdo con la Junta de Coroneles para levantar mil hombres vestidos, reclutados en Andalucía, que serían entregados en Cartagena a cambio de 25000 ducados (a 25 por soldado). De la misma forma solicitó la entrega de una patente de maestre de campo, otra de sargento mayor, dos de ayudante de sargento mayor y diez de capitán; además de dos mercedes de hábito, una para él y otra para su hijo ${ }^{61}$. En este caso fue capaz de cumplir con su ofrecimiento, pues a mediados de octubre de 1638 ya había entregado 1056 unidades $^{62}$.

${ }^{59}$ Consulta de la Junta de las Coronelías, Madrid, 19-10-1637, AGS, GYM, leg. I185. Jiménez Moreno, 201I, PP. 45 I-452; Jiménez Estrella, 20I I, p. 185.

${ }^{60}$ Memorial del marqués de Alconchel solicitando se le despache el título de que se le hizo merced, s.l., s.f. (1650), AHN, Consejos, leg. 4735/II.

${ }^{61}$ Relación de lo que se ha ajustado y asentado con el maestre de campo D. Luis de Monsalve para el cumplimiento de la leva de mil hombres vestidos, que ha de hacer, aprobado y resuelto por S.M. en consulta de 9 de diciembre de 1637, Madrid, 24-12-1637, AGS, GA, leg. 1273.

62 Relación la infantería de las nuevas levas que se ha recibido en la Casa Real de esta ciudad de Cartagena, hasta el 


\section{AGUSTÍN JIMÉNEZ MORENO}

Más o menos por esas fechas D. Juan Fernández de Salinas, que previamente había servido durante dos años en Flandes como alférez, también aceptó reclutar hombres para dicha entidad administrativa, si bien a una escala mucho menor. Este militar ofreció, a mediados de diciembre de 1637, servir con una compañía de 100 hombres aprestada en las poblaciones manchegas de Almagro, Manzanares, Daimiel y El Moral de Calatrava, entregados en Cartagena en un plazo máximo de tres meses. A cambio solicitó la patente de capitán de ella y I500 ducados de plata para asumir los costes del reclutamiento (a I5 ducados por unidad), corriendo por su cuenta todos aquellos que superaran el centenar de efectivos pactados ${ }^{63}$, entregando finalmente $116^{64}$. Características similares se encuentran en el acuerdo signado con el capitán D. Alonso Velázquez de Obando, que acordó servir con 100 hombres. Este servicio, unido a los ya realizados, le permitió ser ascendido poco después a maestre de campo ${ }^{65}$.

A lo largo de las semanas siguientes se decidió enviar la totalidad de los 6000 hombres al norte de Italia, pues se confiaba en cubrir la cuota para Flandes con otras aportaciones, máxime cuando se encontraban en La Coruña cerca de un millar de hombres de las levas realizadas durante el año 1637, y que no se habían embarcado en la armada al mando de Hoces. Por ese motivo, y con la finalidad de reducir en la medida de lo posible el tránsito de los hombres hacia los lugares donde serían entregados a los oficiales reales - tanto para ahorrar costes como para reducir el número de deserciones-, se tuvo a bien permitir que las contribuciones aprestadas en el área andaluza pudieran dirigirse a Cádiz o Cartagena ${ }^{66}$, que se encontraban a una distancia mucho menor de sus jurisdic-

día de la fecha de esta, por cuenta de la Junta de Coroneles, Cartagena, 18-10-1638, AGS, GA, leg. 1272.

${ }^{63}$ Consulta de la Junta de Coroneles. Madrid, I7-I2-1637. AGS, GYM, leg. I I85.

${ }^{64}$ Relación la infantería de las nuevas levas que se ha recibido en la Casa Real de esta ciudad de Cartagena, hasta el día de la fecha de esta, por cuenta de la Junta de Coroneles, Cartagena, 18-10-1638, AGS, GA, leg. 1272.

65 Entre finales de junio y mediados de julio de 1637 alcanzó un acuerdo con el condestable de Castilla para hacerse cargo de reunir un centenar de hombres, correspondientes a la leva que este aristócrata había pactado con la Junta de Coroneles en 1636, recibiendo una de las patentes de capitán que se le habían entregado. Carta del condestable de Castilla a D. Juan de Castro, Madrid, 27-6-1637, AHNOB, Frías, 630/I8. Obligación que el capitán D. Alonso de Obando hizo de entregar en Villalpando 50 hombres, de los 100 de la leva que ha asentado con el condestable de Castilla, Madrid, 13-7-1637, AHNOB, Frías, 630/207. Y al mismo tiempo aceptó hacerse cargo, tal vez por encargo de la Junta de Coroneles - si bien no he encontrado ninguna prueba documental que lo confirme - de levantar otros 200 (en Madrid y Toledo), los cuales debía conducir hasta la localidad turolense de Alcañiz, a 30 ducados por unidad. Ofrecimiento del capitán D. Alonso de Obando para levantar 200 hombres, Madrid, 30-6-1637, AGS, GYM, leg. I I85. Relación de los medios con que el capitán D. Alonso de Obando acepta levantar 200 hombres, AGS, GYM, leg. I I85. Durante los años siguientes continuó con esta lucrativa actividad, convirtiéndose en uno de los principales reclutadores al servicio de la Corona. Rodríguez Hernández, 2016, pp. 489-490.

${ }^{66}$ Así se planteó que el asistente de Sevilla (300 hombres) y los corregidores de Jerez de la Frontera (200), Écija (150), Baeza (100), Jaén (100), Alcalá la Real (50), Carmona (50) y Ronda (50) entregaran sus efectivos 


\section{LA ADMINISTRACIÓN REAL Y LA MOVILIZACIÓN DE LOS RECURSOS}

ciones que Tortosa, donde finalmente llegaron poco más de 800 unidades —alrededor del $13 \%$ del total-, procedentes de las localidades castellanas más cercanas $^{67}$.

Pero las necesidades militares que exigía la defensa de un imperio a escala mundial eran insaciables, $y$ ante esa circunstancia no era de extrañar que cualquier intento de planificación saltara por los aires debido a alguna emergencia. Esto fue lo que ocurrió a principios de enero de 1638, cuando la Junta de Armadas puso de manifiesto la escasez de soldados de infantería para los 10 navíos que formarían parte de una armada conjunta hispano-portuguesa con destino a Brasil ${ }^{68}$. Ante esta eventualidad, se optó por asignar unos 400-500 hombres de las levas efectuadas por la Junta de Coroneles, y que debían ser entregados en Cádiz ${ }^{69}$.

Poco a poco se fueron produciendo avances, y a principios de abril de 1638 se consideraba factible que antes de la conclusión de ese mes se encontraran en Cartagena al menos 2500 hombres $^{70}$. Los resultados finales fueron bastante satisfactorios, pues antes de finales del mes de diciembre habían llegado allí algo más de 5100 hombres — sumando oficiales y soldados- ${ }^{71}$, que sumados a los aproximadamente 400-500 hombres que se embarcaron en Cádiz en los navíos con destino a Brasil, y los 800 entregados en Los Alfaques, elevarían hasta los 6300-6400 el número final de efectivos reclutados gracias a la intervención de la Junta de Coroneles.

en Cádiz. Mientras que los corregidores de Granada (200 unidades), Antequera (I50), Córdoba (I50), Málaga (I50), Guadix (100), Alcalá de Henares (100), Alcaraz (100), Cazorla (50), San Clemente (50) y Talavera de la Reina (50) podrían hacerlo en Cartagena. Consulta de la Junta de Coroneles, I0-I I-I637, AGS, GYM, leg. I 185. Consulta de la Junta de Coroneles, Madrid, 24-I I-1637, AGS, GYM, leg. 1185.

${ }^{67}$ Consulta de la Junta de Coroneles. Madrid, I5-12-1637. AGS, GYM, leg. I I85.

${ }^{68}$ Es posible que se trate de la armada comandada por D. Fernando Mascareñas, conde de la Torre, compuesta por 4 I navíos ( 18 de los cuales integraban la escuadra de Castilla, al mando de D. Juan de Vega Bazán y con D. Francisco Díaz Pimienta como almirante) que tenía como misión expulsar a los holandeses de Pernambuco. Tras muchas dilaciones, esta fuerza naval zarpó a finales de 1638 y llegó a las costas brasileñas en enero de 1639; sin embargo, esta expedición no pudo alcanzar el objetivo para el que se había formado. Fernández Duro, 1898, pp. 132-134; Pérez de Tudela y Bueso, 1974; Valladares Ramírez, 2006.

${ }^{69}$ Consulta de la Junta de Armadas, Madrid, I3-I-1638, AGS, GYM, leg. 3170.

${ }^{70}$ Consulta de la Junta de Ejecución del Ejército, Madrid, 8-4-1638, AGS, GYM, leg. 1215. Consulta de la Junta de Ejecución del Ejército, Madrid, I0-4-1638, AGS, GYM, leg. 1215.

${ }^{71}$ Carta de Rodrigo de Moreda al secretario D. Fernando de Contreras sobre las levas que han entrado en Cartagena y los que efectivamente se han embarcado, Cartagena, 6-12-1638, AGS, GYM, leg. 1272. Relación de Rodrigo Moreda de la infantería de las nuevas levas que se han conducido a la Casa Real de Cartagena para pasar a Italia y otras partes, desde 4 de febrero hasta el día de la fecha de hoy, Cartagena, 27-12-1638, AGS, GYM, leg. 1272. 
AGUSTÍN JIMÉNEZ MORENO

Cuadro 4. Hombres entregados en Cartagena por cuenta de la Junta de Coroneles para servir en Italia durante el año 1638. Fuente: AGS, GYM, leg. 1272.

\begin{tabular}{l|r}
\hline \multicolumn{1}{c|}{ Reclutador } & Hombres \\
\hline Asistente de Sevilla & 295 \\
\hline Capitán D. Alonso Velázquez de Obando & 100 \\
\hline Capitán D. Fernando de Rivera & 105 \\
\hline Capitán D. Juan Fernández de Salinas & 116 \\
\hline Capitán D. Rodrigo de Mendoza & 85 \\
\hline Capitán Diego Díaz & 34 \\
\hline Corregidor de Alcaraz & 123 \\
\hline Corregidor de Carmona & 40 \\
\hline Corregidor de Córdoba & 98 \\
\hline Corregidor de Chinchilla y Albacete & 109 \\
\hline Corregidor de Écija & 100 \\
\hline Corregidor de Granada & 56 \\
\hline Corregidor de Guadix, Baza y Almería & 38 \\
\hline Corregidor de Murcia & 122 \\
\hline Corregidor de Palencia & 21 \\
\hline Corregidor de Soria' & 134 \\
\hline D. Diego Cabrera y D. Fernando Mejía & 88 \\
\hline Duque de Arcos & 946 \\
\hline Maestre de Campo D. Luis de Monsalve & 1056 \\
\hline Marqués de Estepa & 130 \\
\hline Marqués de la Hinojosa & 307 \\
\hline Marqués de Priego & 1000 \\
\hline & $\mathbf{5 1 0 3}$ \\
\hline \hline
\end{tabular}

' La contribución de Soria quedó establecida en 100 unidades. El representante de la Corona en esa jurisdicción solicitó a la Junta de Coroneles una patente de capitán en blanco para facilitar la leva, y que recayera en D. Pedro Hurtado de Mendoza. Su último empleo había sido el de alférez de la compañía del maestre de campo D. Juan de Aguirre, máximo responsable del tercio de Álava, que había formado parte del ejército de Labort, participando en la invasión del suroeste francés y la defensa de las plazas adquiridas a finales de 1636, hasta que su compañía fue disuelta y perdió su empleo. Consulta de la Junta de Coroneles. Madrid, 5-12-I637. AGS, GYM, leg. 1185.

Al igual que en los servicios analizados en las páginas precedentes, las levas de la Junta de Coroneles se vieron incrementadas por las aportaciones de otros reclutadores. En este caso se trató de los 1483 hombres que el marqués de la Hinojosa aprestó por encargo del Consejo de Guerra; así como de otros 158 soldados procedentes de la leva efectuada para remitir infantería a los presidios, que fueron incorporados a las fuerzas que debían partir con destino a Italia, por 


\section{LA ADMINISTRACIÓN REAL Y LA MOVILIZACIÓN DE LOS RECURSOS}

lo que la cifra total que se consiguió reunir en Cartagena ascendió hasta las 6744 plazas, de las que se embarcaron $5920^{72}$.

En lo tocante al contingente reunido en Cartagena por mediación de la Junta de Coroneles, se embarcaron 4546 (el 90\%); mientras que 307 (7\%) murieron; 88 soldados no llegaron a embarcarse $(2 \%)$ y los 47 restantes (1\%) corresponden al número de desertores e individuos que no llegaron a sentar plaza al ser rechazados por los oficiales reales ${ }^{73}$.

\subsection{Nuevos reclutamientos para Flandes e Italia (I639-1 640)}

A mediados del mes de enero de 1639 el monarca volvió a dirigirse a la Junta de Coroneles para que aprestara más hombres. El acontecimiento que desencadenó esta nueva petición fue la caída de la fortaleza de Breisach —ubicada en Alsacia y defendida por un contingente imperial- a manos del ejército de Bernardo de Sajonia-Weimar, militar alemán al servicio de Francia, en diciembre de 1638 - tras seis meses de asedio- ${ }^{74}$. Se trataba de una posesión estratégica, porque mantenía las comunicaciones entre Flandes, Milán y el Imperio, cuya pérdida supuso el bloqueo del Camino Español y la imposibilidad de enviar refuerzos a los Países Bajos por vía terrestre, y también que pudieran llegar a la Península regimientos de infantería alemana para participar en la defensa de la frontera pirenaica ${ }^{75}$.

Ante esta situación Felipe IV ordenó a la Junta que aprestara otros 5000 soldados. Si bien las dificultades financieras, que ya se vislumbraron el año I637, amenazaron con impedir la puesta en marcha de esta iniciativa. No obstante, el verdadero problema no era de falta de fondos, sino que se trataba de un problema de liquidez, pues según reconocía la propia Junta disponía de unos 250000 ducados, cantidad suficiente para reclutar alrededor de 9600 hombres, a una media de 25-26 ducados por unidad, que era el precio habitual en esta clase de servicios $^{76}$.

\footnotetext{
72 Relación de Rodrigo Moreda de la infantería de las nuevas levas que se han conducido a la Casa Real de Cartagena para pasar a Italia y otras partes, desde 4 de febrero hasta el día de la fecha de hoy, Cartagena, 27-12-1638, AGS, GYM, leg. 1272. En esta ocasión, el viaje de las fuerzas de infantería reunidas para servir en Italia se realizó de manera escalonada a lo largo del año 1638, empleándose para ello las escuadras de galeras de España, Génova y Nápoles.

${ }^{73}$ Relación de Rodrigo Moreda de la infantería de las nuevas levas que se han conducido a la Casa Real de Cartagena para pasar a Italia y otras partes, desde 4 de febrero hasta el día de la fecha de hoy, Cartagena, 27-I2-I638, AGS, GYM, leg. 1272.

74 Elliott, 1990. pp. 594-595; Parrott, 200I, PP. I29-I30 y 138-139; Parker, 2003. p. 198; Negredo del Cerro, 2016, pp. 237-24I; Wilson, 2018, pp. 174-I8I.

${ }^{75}$ Consulta de la Junta de Coroneles, Madrid, I7-I-1639, AGS, GYM, leg. 1258.

${ }^{76}$ Consulta de la Junta de Coroneles, Madrid, I7-I-1639, AGS, GYM, leg. 1258.
} 


\section{AGUSTÍN JIMÉNEZ MORENO}

Sin embargo, en esos momentos solo podía disponer de unos 100000 ducados: 50000 procedentes de la cantidad que aún no había gastado de lo obtenido por la venta de las licencias para introducir artículos prohibidos; y los otros 50000 de la suma que debían depositar ante la Junta de Coroneles los arrendadores de los almojarifazgos de Sevilla ${ }^{77}$, que en un principio ascendía a 100000 ducados, pero que se habían visto reducidos a la mitad porque la administración real ordenó destinar 50000 ducados de esa partida al mantenimiento de la escuadra de galeras de España ${ }^{78}$. Para compensar el desvío de estos fondos, a la espera de que fueran reintegrados a la Junta, se pusieron a su disposición los 4000 capotes y medias que se habían preparado para uniformar a otros tantos hombres ${ }^{79}$, que habrían de constituir el denominado ejército de Burgos -el cual finalmente no llegó a formarse-, con los cuales podría atender parcialmente las necesidades de vestuario de los hombres que fuera alistando.

En cuanto al resto, procedían de expedientes que, por un motivo u otro, no generaron ingresos inmediatos. Uno de ellos eran los 87000 ducados que debían pagar los comerciantes extranjeros, establecidos en Málaga y Antequera, a cambio del desembargo de sus mercancías - procedentes del comercio ilegal ${ }^{80}$, pues se trataba de una suma pagadera en varias anualidades - cinco en el caso de la primera y tres en el de la segunda-. Otra fuente de ingresos procedió de la venta de un título de vizconde, concedido por la Corona a la Junta para atender a sus compromisos, el cual fue adquirido por D. Pedro Alfonso Flores Montenegro ${ }^{81}$ por 15000 ducados. En este supuesto el principal problema

\footnotetext{
77 Era una renta aduanera que comprendía a toda la costa sur peninsular, desde la frontera con Portugal hasta el límite con la Corona de Aragón, que gravaba la entrada de mercancías. En esos momentos su percepción, al igual que otras muchas rentas reales, se encontraba en manos privadas mediante el sistema de arrendamiento. Domínguez Ortiz, 1960, p. 212.

${ }^{78}$ Consulta de la Junta de Coroneles, Madrid, I7-I-1639, AGS, GYM, leg. 1258.

${ }^{79}$ Consulta de la Junta de Coroneles, Madrid, I7-I-I639, AGS, GYM, leg. 1258

${ }^{80}$ Alloza Aparicio, 2003, sobre todo pp. 237-248.

${ }^{81}$ Natural de la ciudad de Los Reyes (actual Lima), en el virreinato de Perú, donde nació en torno al año I587. Hijo de D. Juan Gutiérrez Flores, caballero de Alcántara y alguacil mayor de la Inquisición de dicha ciudad, oriundo de las Brozas (Cáceres); y de Dña. Lucía de Montenegro, nacida en la misma ciudad que su hijo. Fue señor de Peñaparda de las Flores, Flores de Payo, Flores del Villar y Flores de Casillas. En 1623 ingresó en la orden de Santiago, y en septiembre de 1638 fue honrado - previo pago de los 15000 ducados referidoscon el título de vizconde de Peñaparda de las Flores. Ostentó el empleo de alférez mayor perpetuo de las Brozas y alguacil mayor perpetuo de preeminencia de la villa de Alcántara. A finales de 1647 o principios de 1648 pidió que su vizcondado fuera elevado a condado, aunque no consiguió su objetivo. No obstante, poco después fue nombrado corregidor de Córdoba, si bien su gestión dejó bastante que desear y tuvo una gran responsabilidad en el motín que estalló en 1652. Su último empleo fue el de corregidor de Valladolid, que sirvió hasta su muerte en agosto de 1664. Memorial del vizconde de Peñaparda solicitando que, en consideración de los servicios de su casa y los suyos, le honre con el título de conde de Peñaparda, s.l., s.f. (principios de 1648), AHN, Consejos, leg. 4735/I9. AHN, OO.MM., Caballeros-Santiago, Expediente 3095. Ramos, Aparato para la corrección, pp. 102-103; Lohmann Villena, 1993, pp. 16I-I62; Gelabert, 200I, pp. 335-34I.
} 


\section{LA ADMINISTRACIÓN REAL Y LA MOVILIZACIÓN DE LOS RECURSOS}

residía en el hecho de que esa cantidad había sido abonada en las Indias, y no podría ser disfrutada hasta la llegada a Sevilla de la flota que transportaba el tesoro americano ${ }^{82}$ - lo cual no se produciría hasta el mes de julio de 1639-.

Pero a los gastos habituales que debía afrontar la Junta de Coroneles, en esta ocasión se cargó sobre ella otro más: el transporte de los soldados hasta los teatros de operaciones donde finalmente servirín. Para ello llegó a un acuerdo con Benjamin Wright ${ }^{83}$, hombre de negocios inglés, que jugó un activo papel en esta materia durante la primera mitad del año 1639. Con la finalidad de atender a estos nuevos gastos, la Corona autorizó a la Junta a llegar a acuerdos con particulares para que, a cambio del desembolso de ciertas cantidades en metálico, fueran honrados con mercedes honoríficas. Esto fue lo que ocurrió con el maestre de campo D. Alonso Celdrán de Bolea ${ }^{84}$, un miembro de la pequeña nobleza aragonesa, señor de Sobradiel, que a principios del mes de abril de 1639 ofreció 70000 reales en plata (algo más de 6300 ducados), los cuales se destinaron a costear parte del transporte de los 5000 hombres que Wright se había comprometido a llevar a Italia ${ }^{85}$, a cambio de la concesión de un título de marqués o

82 Consulta de la Junta de Coroneles, Madrid, I7-I-1639, AGS, GYM, leg. 1258.

83 Entre los meses de febrero y abril de 1639, suscribió cuatro asientos con la Junta de Coroneles para transportar y abastecer hasta la llegada a su destino, a 14200 soldados. El primero de ellos tuvo lugar a finales de febrero de 1639, para conducir 1500 hombres desde Cádiz hasta Dunquerque, a un precio de 337 reales - alrededor de 30 ducados y medio- por soldado. Según refiere Gil Martínez, la Junta de Vestir la Casa abonó 100000 reales de plata para el pago de este asiento, que posteriormente serían reintegrados por la Junta de Coroneles, en este caso con los ingresos procedentes de los almojarifazgos. Consulta de la Junta de Coroneles. Madrid, 16-2-1639, AGS, GYM, leg. I26I. Gil Martínez, 2017, pp. 7I (nota 37) y 250. El segundo fue signado en el mes de marzo, y pretendía transportar otros 3500 infantes, en este caso desde La Coruña a Dunquerque a 300 reales por plaza. El tercero se suscribió ese mismo mes, por un total de 4200 unidades; 3000 desde Cartagena a Dunquerque (a 400 reales cada uno) y 1200 desde los presidios norteafricanos al puerto guipuzcoano de Pasajes (a 300 reales/hombre). El cuarto y último se produjo en el mes de abril, para llevar a suelo italiano (Génova), 5000 efectivos desde los puertos de Cartagena, Málaga y Los Alfaques (Tarragona), a un precio de 180 reales cada uno. Consulta de la Junta de Coroneles, Madrid, I5-3-1639, AGS, GYM, leg. 1258. Sin embargo no todos llegaron al frente, pues los holandeses fueron capaces de interceptarlos antes de que los hombres pudieran desembarcar. Esto fue lo que ocurrió con el contingente que zarpó de Cádiz en el mes de mayo con los 1500 hombres referidos, pues cayeron en mano del enemigo tres navíos en los que viajaban unos 700 efectivos. Taylor, 1972, Pp. 254-255; Alcalá-Zamora y Queipo de Llano, 1975, PP. 4I5-416; Stradling, 1992, Pp. 147-149; Alloza Aparicio y Zofío Llorente, 2013, pp. 682-686.

${ }^{84}$ Hijo de D. Jerónimo Celdrán, baile general y escribano de ración del reino de Aragón, y de Dña. Elena Abarca de Bolea. Fue miembro de las Cortes de Aragón, participando en las que se celebraron el año I626, y poco después sentó plaza en el ejército de Milán, participando en la Guerra de Mantua. A la conclusión de ese conflicto regresó a Aragón, obteniendo una de las comisarías encargadas de la cobranza del donativo del año 1632. En 1638 participó, junto con su séquito, en el socorro de Fuenterrabía; y a finales de ese año llegó a un acuerdo con la Junta de la Ejecución para hacerse cargo de una leva de 600 hombres, con los cuales se le formó un tercio, entregándosele dos mercedes de hábito como gratificación. Papel del secretario $D$. Fernando de Contreras a la secretaría del Consejo de las Órdenes, Madrid, 27-I-I639, AHN, OO.MM., leg. I04(2), núm. I I5. Consulta de la Junta de Coroneles. Madrid, I0-4-1639, AGS, GYM, leg. I26I.

85 Alloza Aparicio y Zofío Llorente, 2013, p. 687. 


\section{AGUSTÍN JIMÉNEZ MORENO}

conde en el Reino de Aragón ${ }^{86}$, siendo honrado en el mes de junio con el condado de Sobradiel ${ }^{87}$.

A finales de enero de 1639 la Junta de Coroneles presentó a la Corona un proyecto en el que esperaba aprestar unos 9100 efectivos, entregados en los puertos de La Coruña, Málaga y Cádiz ${ }^{88}$. De ellos, unos 6000 correspondían a las levas pactadas con ocho maestres de campo, que se comprometieron a presentar contingentes que iban desde las 500 hasta las 1000 unidades, por un total de 156100 ducados - casi 26 ducados por hombre- ${ }^{89}$; mientras que el resto procedían de aportaciones de la nobleza y particulares, que a cambio de alguna merced aceptaron servir con un número de hombres variable.

Entre ellos se encontraba D. Juan Vicentelo Leca y Toledo, primer conde de Cantillana ${ }^{90}$, quien en abril de 1636 había sido condenado a 10 años de destierro en Orán por un incidente en palacio que había tenido lugar a finales de diciembre de 1635'. No fue hasta el mes de octubre de 1638 cuando el duque de Medina Sidonia, en nombre del conde de Cantillana, se dirigió al conde duque de Olivares para transmitirle el ofrecimiento de este aristócrata de costear 100 soldados a cambio del perdón real ${ }^{92}$.

${ }^{86}$ Consulta de la Junta de Coroneles, Madrid, 10-4-1639, AGS, GA, leg. 1261.

${ }^{87}$ Ramos, Aparato para corrección, p. 38.

${ }^{88}$ Relación de las personas con quien se han ajustado levas por la Junta de Coroneles, el número de gente y la parte a donde la han de conducir, s.l., s.f. (principios de enero de I639), AGS, GYM, leg. I 258.

${ }^{89}$ Se trataba de los maestres de campo D. Juan Francisco Cordero, D. Diego Jaraba, D. Simón de Mascareñas, D. Luis de Monsalve, D. Fernando del Pulgar, D. Luis de Quiroga, D. Luis Jorge de Rivera y D. Francisco de Torres. Relación de los gastos de las levas ajustadas por la Junta de Coroneles, s.l., s.f. (marzo de I639), AGS, GYM, leg. 1258.

90 Linaje de origen italiano, concretamente de la isla de Córcega -en esos momentos bajo dominio de la república genovesa-, que gracias al comercio indiano accedió a la nobleza, si bien de forma progresiva. Pues primero, en abril de 1567, Juan Antonio Corzo Vicentelo de Leca fundó el mayorazgo de Cantillana, Villaverde y Brenes, convirtiéndose en el primer señor de Cantillana. En abril de I6I I, Felipe III honró a su nieto, D. Juan Antonio Vicentelo de Leca y Toledo, con el marquesado de Cantillana. Vila Villar, 199I.

${ }^{9}$ El hecho que desencadenó todo fue una discusión entre el marqués del Águila, yerno del conde de Cantillana, y D. Juan de Herrera, caballero de Santiago y caballerizo del conde duque, durante una representación teatral, en la cual Cantillana intervino en defensa de su yerno, que fue presenciada por los reyes. Los participantes en esta disputa fueron castigados con severidad, recibiendo la condena más dura el marqués del Águila, sentenciado con la pena capital -en rebeldía, pues había huido-. Mientras que en el caso del conde de Cantillana, tras ser arrestado y encarcelado en el castillo de Montánchez, además de los 10 años de destierro en Orán, donde debía servir personalmente junto con cuatro lanzas costeadas por él, se le prohibió acercarse a menos de 20 leguas de la Corte durante el resto de su vida. De la misma forma se le impuso una multa de 2000 ducados, y fue desprovisto del empleo de gentilhombre de la cámara del Cardenal Infante. Urbina y Ceballos-Escalera, 1900. pp. I19-121; Domínguez Ortiz, 1973, pp. 158-161; Gascón de Torquemada, Gaceta y nuevas de la Corte, p. 390; Martínez Hernández, 2014, p. 295; Guillén Berrendero, 2019, pp. 51-52; Gómez Vozmediano, 2019, p. 100.

${ }^{92}$ Consulta de la Junta de Coroneles, Madrid, 28-10- 1638, AGS, GYM, leg. 1258. 


\section{LA ADMINISTRACIÓN REAL Y LA MOVILIZACIÓN DE LOS RECURSOS}

Olivares aceptó la propuesta y remitió este asunto a la Junta de Coroneles. Pero el levantamiento del destierro le iba a salir al conde de Cantillana mucho más caro, ya que este organismo planteó que su contribución fuera de medio millar de hombres, entregados en el puerto de Cartagena. En el tira y afloja característico en este tipo de negociaciones, el conde de Cantillana aceptó servir con 400 hombres, concediéndosele cuatro patentes de capitán en blanco para ayudarle a cumplir con su misión, comprometiéndose a entregar los soldados a lo largo del mes de febrero de 1639. Sin embargo, la Junta creía que el conde de Cantillana podía llegar hasta las 500 unidades, que fue la cifra final en la que quedó tasado este servicio ${ }^{93}$. Por otro lado, se aceptó su petición de entregar los hombres en Cádiz, al tiempo que se le concedió permiso para vender un cortijo vinculado a su mayorazgo ${ }^{94}$ y una patente de capitán más ${ }^{95}$. A principios del mes de noviembre de 1638 ya había entregado 384 soldados, por lo que únicamente quedaban pendientes $116^{96}$, que fueron presentados entre finales de diciembre de 1639 y las primeras semanas del año siguiente ${ }^{97}$.

Las aportaciones de la Junta se vieron complementadas con otra iniciativa de la Corona, cuyas primeras noticias datan de mediados del mes de noviembre de 1638. En esa ocasión Felipe IV ordenó la realización de una nueva leva para remitir infantería a los presidios ${ }^{98}$. Este nuevo servicio pretendía reunir los cerca de $\mathbf{8 0 0 0}$ hombres que, según los cálculos de la administración real, faltaban para que estas fortalezas fronterizas tuvieran las 18000 plazas que debían presentar, encomendado esa tarea a los corregidores castellanos, que debían reclutar un soldado por cada 100 vecinos, quedando exentos aquellos lugares con menos de $50^{99}$, motivo por el cual pasó a denominarse leva del uno por ciento. En esta ocasión se decidió incluir a la nobleza titulada ${ }^{100}$ y las localidades bajo jurisdicción de las

${ }^{93}$ Consulta de la Junta de Coroneles, Madrid, 28-10- 1638, AGS, GYM, leg. 1258.

${ }^{94}$ Consulta de la Junta de Coroneles, Madrid, I7-I-1639. AGS, GYM, leg. 1258.

${ }^{95} \mathrm{~A}$ finales de marzo de ese año solicitó que le entregaran otras tres patentes más, facilitándose otras dos. De manera que finalmente recibió siete para reunir los 500 hombres en cuestión. Consulta de la Junta de Coroneles, Madrid, 22-3-1639, AGS, GYM, leg. 1258.

96 Relación de la gente que ha entrado en este presidio de Cádiz desde 23 de enero pasado de este año hasta 23 de este presente mes de mayo inclusive. Cádiz, 23-5-1639. AGS, GYM, leg. 126I. Certificación de la gente que ho entregado el conde de Cantillana desde el 8 de noviembre de 1638 hasta 4 de noviembre de 1639, Cádiz, 4-1 I1639, AGS, GYM, leg. 1258

${ }^{97}$ Certificación del secretario Pedro de Villanueva, de que el conde de Cantillana ha entregado los 500 hombres que hubo de levantar por el alzamiento de su destierro, Madrid, I8-3-1640, AGS, GYM, leg. 1258.

${ }^{98}$ Real Orden dirigida al Reino mandando se haga un nuevo repartimiento de gente para los presidios, Madrid, I6-II1638, AHN, Consejos, leg. $5 \mathrm{I} 446$.

${ }^{99}$ Consulta del Reino sobre la orden en que V.M. manda se cumplan los 8037 soldados que faltan para los presidios, Madrid, 2I-12-1638, AHN, Consejos, leg. 51446.

100 En este caso se solicitó a 34 nobles un contingente que ascendía a 1950 hombres. No obstante, había 


\section{AGUSTÍN JIMÉNEZ MORENO}

Órdenes Militares ${ }^{101}$, que debían entregar sus contingentes al corregidor más cercano, recayendo la responsabilidad final de todo ello sobre la Junta de Coroneles. Aunque la necesidad de efectivos para la defensa de la posición española en Europa ocasionó que el proyecto original se modificara, y que de los referidos 8000 hombres se planteara el envío a Flandes e Italia de unos 5000-6000, mientras que a los presidios únicamente se destinarían, como mucho, entre 20003000 unidades $^{102}$. Además, se solicitó a los reinos de la Corona cierto número de hombres, si bien su asistencia no se vinculó a esta leva, sino que cada uno debía entregar una cuota determinada: 600 Valencia, 400 Aragón y $130 \mathrm{Ma}-$ llorca ${ }^{103}$. De este modo, sumando todas las aportaciones, la Junta pretendía reunir entre 15 000-16 000 infantes.

En esta ocasión, los hombres aprestados por la Junta de Coroneles también fueron empleados para cubrir otras necesidades que no tenían nada que ver con lo contemplado en un principio. Así, entre finales de marzo o principios de abril de ese año, el duque de Medina Sidonia - capitán general del Mar Océano y costas de Andalucía-, ordenó sacar del presidio de Cádiz 700 hombres de los enviados por la Junta para servir en Países Bajos ${ }^{104}$. El destino de estos efectivos fue una armada compuesta por ocho urcas, cuyo mando recayó en el almirante D. Francisco Rodríguez de Ledesma, que zarpó de Cádiz con destino a Veracruz para escoltar a la flota de Indias que ese año comandaba el general D. Carlos de lbarra, y que había sufrido importantes daños tras desbaratar (en agosto-septiembre de 1638) un ataque holandés a la altura de Cuba que pretendía, al igual que sucedió en 1628, apoderarse de la plata que transportaban ${ }^{105}$.

\footnotetext{
considerables diferencias entre ellos, pues la contribución más importante fue la pedida al duque de Escalona, consistente en 200 hombres, seguida de la de los duques de Alba, Arcos, Béjar, Cardona, Lerma, Osuna, Medina Sidonia; y los marqueses de Priego y la Floresta, que ascendió a un centenar de efectivos. Por el contrario, el duque de Pastrana, el marqués de Malpica y el conde de Coruña solo debían presentar 20 unidades; y el conde de Casarrubios 10. Relación de los señores a quienes se han encargado levas por la Junta de Coroneles, s.l., s.f. (principios de I639), AGS, GYM, leg. I 346.

${ }^{101}$ En un primer momento se pidió al Consejo de Órdenes que entregara 150 hombres, alistados en los lugares bajo su jurisdicción, que poco después se incrementó en 50 unidades más, y otras 50 reclutadas en los prioratos. Pero en el mes de marzo se decretó aumentar aún más el número de hombres a entregar, quedando establecido en 400. Jiménez Moreno, 2014, pp. 342-343; Rodríguez Hernández, 2017, p. 168.

102 Relación de los gastos de las levas ajustadas por la Junta de Coroneles, s.l., s.f. (marzo de I639), AGS, GYM, leg. 1258. Finalmente consiguió reclutar unos 5000 hombres, corriendo por su cuenta el coste del vestuario y transporte, que ascendió a 600000 reales (unos 54500 ducados). Consulta de la Junta de Ejecución, Madrid, 12-2-1640, AGS, GYM, leg. 1326.

${ }^{103}$ También se pidió al virrey de Cataluña que realizara una leva, si bien no he podido averiguar su cuantía. Relación de las personas con quien se ha ajustado levas por la Junta de Coroneles, y también de los corregidores y señores por razón de la leva del uno por ciento hasta 24 de febrero, s.l., s.f. (marzo de 1639), AGS, GYM, leg. 1258. Rodríguez Hernández, 2017, p. 169.

104 Consulta de la Junta de Coroneles, Madrid, I6-4-I639, AGS, GYM, leg. I26I.

${ }^{105}$ Fernández Duro, 1898, pp. 191-196
} 
LA ADMINISTRACIÓN REAL Y LA MOVILIZACIÓN DE LOS RECURSOS

Cuadro 5. Levas en las que participó la Junta de Coroneles durante la primera mitad de 1639 Fuentes: AGS, GYM, legs. 1258, 126I, 1273, 1326

\begin{tabular}{|c|c|c|c|}
\hline Reclutador & $\begin{array}{c}\text { Efectivos teóricos } \\
\text { a reclutar }\end{array}$ & $\begin{array}{c}\text { Hombres } \\
\text { entregados }\end{array}$ & $\begin{array}{l}\text { Lugar de } \\
\text { entrega }\end{array}$ \\
\hline Conde de Cantillana & 500 & 500 & Cádiz \\
\hline Conde de Grajal & $\begin{array}{r}250 \\
\text { (Vestidos) }\end{array}$ & ¿? & La Coruña \\
\hline Corregidores y títulos & $\begin{array}{r}5000 \\
\text { (Vestidos) }\end{array}$ & 5000 & $\begin{array}{l}\text { La Coruña, } \\
\text { Málaga, Cádiz, } \\
\text { Cartagena y } \\
\text { Tortosa }\end{array}$ \\
\hline D. Alonso Velázquez de Obando & $\begin{array}{r}500 \\
\text { (Vestidos) }\end{array}$ & $\begin{array}{r}300 \\
\text { (Hasta finales de } \\
\text { febrero de } 1639 \text { ) }\end{array}$ & La Coruña \\
\hline D. Diego Jacaba del Castillo & 700 & 703 & La Coruña \\
\hline D. Fernando de Meneses Pacheco y Silval & 90 & 50 & La Coruña \\
\hline D. Fernando del Pulgar & 1000 & 1000 & Málaga \\
\hline D. Francisco de Torres Castejón ${ }^{2}$ & $\begin{array}{r}600 \\
\text { (Vestidos) }\end{array}$ & 838 & Málaga \\
\hline D. Francisco Pérez de Guzmán & $\begin{array}{r}50 \\
\text { (Vestidos) }\end{array}$ & ¿? & Cartagena \\
\hline D. Fernando Mansilla Chacón & $\begin{array}{r}50 \\
\text { (Vestidos) }\end{array}$ & 50 & Málaga \\
\hline D. Gaspar de Rozas & $\begin{array}{r}50 \\
\text { (Vestidos) } \\
\end{array}$ & ¿? & Cartagena \\
\hline $\begin{array}{l}\text { D. Juan de Contefiesco y D. Francisco } \\
\text { Romero }\end{array}$ & $\begin{array}{r}200 \\
\text { (Vestidos) }\end{array}$ & 200 & Cartagena \\
\hline D. Juan de Gondra & $\begin{array}{r}100 \\
\text { (Vestidos) }\end{array}$ & 100 & Cartagena \\
\hline D. Juan Francisco Cordero & 1000 & 558 & La Coruña \\
\hline $\begin{array}{l}\text { D. Juan Ramírez de Arellano, marqués de } \\
\text { la Hinojosa }\end{array}$ & 1450 & 1450 & $\begin{array}{l}\text { La Coruña y } \\
\text { Tortosa }\end{array}$ \\
\hline D. Lorenzo Garele & $\begin{array}{r}50 \\
\text { (Vestidos) } \\
\end{array}$ & 50 & Cartagena \\
\hline D. Luis de Monsalve & 1000 & $727^{3}$ & Málaga \\
\hline D. Luis de Quiroga & $\begin{array}{r}550 \\
\text { (Vestidos) }\end{array}$ & 555 & Cartagena \\
\hline D. Luis Jorge de Rivera & 500 & 341 & Málaga \\
\hline D. Pedro González de Mendoza & $\begin{array}{r}25 \\
\text { (La mitad vestidos) } \\
\end{array}$ & 25 & Cartagena \\
\hline D. Simón de Mascareñas & 600 & 600 & Málaga \\
\hline Leva del reino de Aragón & 400 & ¿? & Tortosa \\
\hline Leva del reino de Mallorca & 130 & ¿? & Tortosa \\
\hline Leva del reino de Valencia & 600 & ¿? & Tortosa \\
\hline \multirow[t]{2}{*}{ Rolando Levanto } & $\begin{array}{r}100 \\
\text { (Vestidos) }\end{array}$ & 101 & Cartagena \\
\hline & 15495 & 13148 & \\
\hline
\end{tabular}

'Se trataba de los 90 hombres que estaban pendientes de entrega, correspondientes al servicio que había pactado en octubre de 1637 con la Junta de Coroneles, de los cuales ya había entregado 210 en Barcelona.

2 Sobre este individuo, y su trayectoria reclutadora al servicio de la Corona, Rodríguez Hernández, 2012.

${ }^{3}$ Se trata de una cifra aproximada, pues en agosto de ese mismo año se comprometió a levantar otros 1000 soldados. Finalmente entregó, sumando ambos servicios, 1454 hombres. De manera que los 727 hombres corresponderían al resultado de dividir entre dos el número total de efectivos. 


\section{AGUSTÍN JIMÉNEZ MORENO}

Pese a que gracias a este socorro se consiguió que la flota llegara intacta a mediados del mes de julio, fue al precio de retrasar la salida de los 1500 hombres que Wright debía llevar desde Cádiz hasta Flandes. Tras la protesta de la Junta, el monarca determinó que el Consejo de Indias la compensara económicamente, por una cantidad de 25000 ducados en plata -a casi 36 ducados por unidad, unos 10 ducados más de lo que solía pagar a los asentistas que reclutaban tropas para ella- ${ }^{106}$. Pero a estos 700 hombres se le unieron pocas semanas más tarde otros 200 , que en esta ocasión fueron destinados a los galeones de la plata al mando del general D. Jerónimo Gómez de Sandoval ${ }^{107}$. En esta ocasión, también se decidió que fuera el Consejo de Indias quien compensara a la Junta de Coroneles por haberse apropiado de sus efectivos, mediante el abono de otros 7.200 ducados en plata ${ }^{108}$.

\section{4. ÚLTIMO SERVICIO Y DESAPARICIÓN (I640-I64I)}

Aunque la Junta de Coroneles ya empezaba a dar señales de agotamiento, motivadas por la falta de fondos, a mediados de 1639 se embarcó en otro reclutamiento para enviar a Italia otros 2000 efectivos, entregados en Málaga y Cartagena. Si bien en las semanas siguientes fue capaz de incrementar este contingente hasta superar los $3000^{109}$. Para ello llegó a un acuerdo con el maestre de campo D. Luis de Monsalve quien debía aprestar otros 1000 hombres, ascendiendo su contribución final a 2000 plazas ${ }^{110}$. También con D. Rodrigo de Silva y Mendoza, cuarto duque de Pastrana, para que a cambio de ciertas mercedes entregara 600 soldados "'. Mientras que los otros 400 correrían por cuenta del capitán D. Jerónimo del Pulgar, hermano del maestre de campo D. Fernando del Pulgar ${ }^{112}$ - pero en última instancia esta leva no llegó a fructificar-. Y a finales de agosto consiguió que el capitán D. Juan de Leyva y Guzmán aceptara servir con otros 1000 hombres presentados en Málaga ${ }^{113}$.

\footnotetext{
106 Consulta de la Junta de Coroneles. Madrid, 2-5-1639. AGS, GYM, leg. 1258. Consulta de la Junta de Coroneles, Madrid, 28-5-1639, AGS, GYM, leg. 1258.

107 Relación de la gente que ha entrado en el presidio de Cádiz desde 23 de enero de este año hasta 23 de este presente mes de mayo por cuenta de la Junta de Coroneles, Cádiz, 23-5-1639, AGS, GYM, leg. I26I. Consulta de la Junta de Coroneles, Madrid, 10-7-1639, AGS, GYM, leg. 1258.

108 Consulta de la Junta de Coroneles, Madrid, 28-I I-I639, AGS, GYM, leg. 1258.

109 Consulta de la Junta de Coroneles, Madrid, I0-6-1639, AGS, GYM, leg. 1335.

110 Consulta de la Junta de Coroneles, Madrid, 29-6-1639, AGS, GYM, leg. 1258.

11 II Jiménez Moreno, 2017b, pp. 432-434.

112 Consulta de la Junta de Coroneles, 10-6-1639, AGS, GYM, leg. 1335.

113 Consulta de la Junta de Coroneles, Madrid, 7-9-1639, AGS, GYM, leg. 1258.
} 


\section{LA ADMINISTRACIÓN REAL Y LA MOVILIZACIÓN DE LOS RECURSOS}

Por esos días se pactó con los capitanes D. Juan Contefiesco y D. Francisco Romero que entregaran en Cartagena otros 200, que sumados a los 200 que previamente debían entregar en virtud del acuerdo suscrito en el mes de febrero, hacían un total de 400. En esta ocasión, además de cinco patentes de capitán, se les entregaron cuatro mercedes de hábito (una por cada 50 hombres) en lugar de los 6000 ducados (a 30 ducados por unidad), en que se tasó esta leva. Esto se debió a que, tal y como reconoció la propia Junta, no tenía dinero para pagarles, optando por entregarles dos mercedes de hábito de manera inmediata, para que con los fondos obtenidos con su venta pudieran comenzar los reclutamientos, lo que evidenciaba los graves problemas financieros que padecía esta entidad administrativa, $y$ que se agravaron en los meses siguientes ${ }^{114}$. $Y$ a finales de diciembre se llegó a un acuerdo con D. Luis Ortiz de Zúñiga, vizconde de Valencina quien, tras unas arduas negociaciones, se comprometió a servir con 360 hombres que debía entregar en Cartagena, a cambio de un título de marqués ${ }^{115}$.

Parte de las dificultades económicas de la Junta de Coroneles se debieron a que los arbitrios concedidos por la Corona para financiar sus actividades no produjeron los fondos esperados. Esto ocurrió con el denominado «medio de las tierras de Jerez»), inscrito en la política regia de recuperación y venta (iniciada a finales de 1635) de las tierras baldías - fincas cuya titularidad pertenecía a la Corona, pero que eran explotadas por los pueblos, ya que gozaban de ciertos derechos comunales sobre ellas- ${ }^{116}$. Cabe la posibilidad de que la Corona decidiera ceder a la Junta la suma obtenida por ese concepto en la localidad gaditana de Jerez de la Frontera, con la esperanza de aliviar su precaria situación. No obstante la resistencia municipal a deshacerse de esos bienes generó una gran conflictividad y una intensa actividad judicial, que paralizó este designio e impidió que la Junta de Coroneles pudiera disfrutar de los fondos que se le habían consignado ${ }^{117}$.

\footnotetext{
114 Consulta de la Junta de Coroneles, 7-9-1258. No obstante, pese a que entregaron la totalidad de los hombres acordados, únicamente recibieron dos mercedes de hábito - correspondientes al precio de 100 unidades-, pues en torno al mes septiembre-octubre de 1640 se decidió que, a pesar de la escasez de fondos de la Junta, se le entregaran los 3000 ducados correspondientes al otro centenar de soldados. No obstante, este organismo no les remitió esa suma, lo que llevó al capitán Contefiesco a ser encarcelado por las deudas que había contraído para la realización de esta leva, y que en mayo de 1645 aún no habían sido saldadas. Memorial de los capitanes D. Juan Contefiesco y D. Francisco Romero, s.l., s.f. (septiembre-octubre de I640), AGS, GYM, leg. 1258. Certificación de Pedro de Villanueva, secretario que fue de la Junta de Coroneles, Madrid, 6-5-1645, AGS. GYM, leg. 1258

115 Consulta de la Junta de Ejecución, Madrid, 3-12-1639, AGS, GYM, leg. I26I. Jiménez Estrella, 20I I, pp. I84-185.

116 A este respecto Domínguez Ortiz, 1984; Calvo Poyato, 1990, pp. 105-109; Lanza García, 2012; Gil Martínez, 2019.

117 Consulta de la Junta de Coroneles, 10-6-1639, AGS, GYM, leg. 1335.
} 


\section{AGUSTÍN JIMÉNEZ MORENO}

Otro de los expedientes que tampoco dio los resultados pretendidos fue la venta de un empleo de capitán de los galeones (galeones de la plata) de la Armada de la Carrera de las Indias ${ }^{118}$. Pese a que la Junta de Coroneles había encontrado un comprador para esta merced, que estaba dispuesto a abonar 50000 reales en plata (algo más de 4500 ducados), la operación no pudo ejecutarse ya que el Consejo de Indias se opuso a ello119. También debía percibir ingresos procedentes de la venta de las escribanías de millones ${ }^{120}$, pues a finales de enero de 1640 solicitó que se ordenara a la persona que gestionaba estos fondos, pusiera a su disposición la cantidad que se le había consignado ${ }^{21}$. Sin embargo, el hecho de que se reclamaran esos caudales indica que, o bien no se entregaron, o no se hizo con la premura necesaria.

Para compensar esta falta de liquidez la Junta suscribió algunos préstamos con particulares. Uno de ellos con Juan Bautista Lamberto, un comerciante de origen genovés ${ }^{122}$, que ostentaba el título de cónsul general de los extranjeros de Cartagena, por un montante de 5200 reales - lo que constituía una suma no demasiado elevada - . A la hora proceder a la devolución de la deuda, la Junta de Coroneles, probablemente a petición del prestamista, solicitó al monarca que en lugar del dinero se le hiciera merced de un empleo de jurado de la ciudad de Cartagena - se trataba de un cargo que, junto al de regidor, tenía una gran importancia en ciertos lugares, entre ellos Murcia y Cartagena, pues entre sus competencias se encontraba la de fiscalizar la hacienda municipal- ${ }^{123}$. Pese a que el monarca dio el visto bueno a esta operación, la Cámara de Castilla emitió un dictamen desfavorable ${ }^{124}$.

La última referencia que he encontrado sobre la venta de un cargo para sufragar los gastos de la Junta de Coroneles, data del mes de abril de 1640. Se trataba del oficio de correo mayor de Cataluña, por el cual había recibido una oferta de 14000 libras catalanas en plata (unos 12600 ducados). Pero en su desesperada búsqueda de nuevos ingresos, consideró oportuno ofrecer el puesto a D. Iñigo de Vélez de Guevara y Tassis ${ }^{125}$, quinto conde de Oñate, correo mayor

\footnotetext{
118 Sobre la importancia de los empleos de capitán de los galeones de la plata, aunque también de las compañías de infantería que viajaban en ellos, así como del mercado venal originado en torno a ellos Díaz Blanco, 20I5, Pp. I 19-124; Andújar Castillo, 2016, pp. 273-274; Andújar Castillo, 2018, pp. 245-246, 248-249.

119 Consulta de la Junta de Coroneles, 10-6-1639, AGS, GYM, leg. 1335.

120 Gil Martínez, 2013, sobre todo pp. 324-327.

${ }^{121}$ Consulta de la Junta de Coroneles, Madrid, 29-I-I640, AGS, GYM, leg. 1336.

122 Sobre este personaje Montojo Montojo, 1993, pp. 260-268.

123 Consulta de la Cámara, Madrid, I8-I-1640, AHN, Consejos, leg. 4428.

124 Consulta de la Cámara, Madrid, 2-4-1640, AHN, Consejos, leg. 4428.

125 Datos biográficos en: http://dbe.rah.es/biografias/2 I233/inigo-velez-de-guevara-y-tassis (Consultado 28-I22019).
} 


\section{LA ADMINISTRACIÓN REAL Y LA MOVILIZACIÓN DE LOS RECURSOS}

de España desde 1623 - y correo mayor de las Indias, por compra, desde $1633^{126}$ - , quien tal vez pudiera estar interesado en agregarlo a los que ya disfrutaba, ofreciendo una cantidad mayor por él ${ }^{27}$. Tal y como previó la Junta, Oñate presentó una contraoferta superior a la inicial, pero lo era únicamente en unos 400 ducados, pues ofreció 13000 en plata, que aliviarían de forma momentánea las exiguas finanzas de la Junta de Coroneles ${ }^{128}$.

A pesar de todo, a finales de enero de 1640, la Junta tenía bastante encauzada la leva de los 3000 hombres para Italia, y además estaba en negociaciones para entregar otros 1500 hombres destinados a la escuadra de galeras de España ${ }^{129}$. Sin embargo, no se trataba más que de un espejismo, pues como consecuencia de la falta de fondos empezaron a paralizarse los reclutamientos. Entre los afectados se encontraba el maestre de campo D. Luis de Monsalve, quien desistió de entregar los 546 hombres que le quedaban para cumplir el asiento de 2000 que había suscrito ${ }^{130}$. En una situación similar se encontraba Diego de Villanueva, contador del Consejo de Órdenes ${ }^{\mid 31}$, quien únicamente fue capaz de reunir 237 de los 400 hombres que se comprometió a presentar ${ }^{132}$.

De la misma forma, en esos instantes y como consecuencia de la falta de liquidez, se intentó potenciar la utilización de las mercedes de hábito como incentivo para facilitar el reclutamiento, ofreciendo una por cada 50 hombres, tal y como se había hecho con los capitanes Contefiesco y Romero. Eso fue lo que

126 Vallejo García-Hevia, 2002, pp. $1788-1789$.

127 Consulta de la Junta de Coroneles, Madrid, 26-4-1640, AGS, GYM, leg. 1336.

${ }^{128}$ Condiciones pactadas entre la Junta de Coroneles y el conde de Oñate para la venta del oficio de correo mayor de Cataluña, s.l., s.f. (mayo de I640), AGS, GYM, leg. 1336.

${ }^{129}$ Relación de la gente ajustada por la Junta de Coroneles, s.I., s.f. (finales de enero de I640), AGS, GYM, leg. I336. Relación de las levas de la Junta de Coroneles y el estado de ellas hasta 27 de enero de 1640 . s.l., s.f. (principios de febrero de 1640), AGS, GYM, leg. 1277.

130 Relación de las personas con quien están ajustadas levas por la Junta de Coroneles, s.l., s.f. (finales de 1640 principios de I64I), AGS, GYM, leg. 1273.

131 En 1638 había firmado un asiento con la Junta de Coroneles para suministrar el vestuario de 2000 soldados - por un total de 260000 reales, a 130 reales cada uno-. Y en abril de 1639 presentó una oferta para entregar la uniformidad de 4000, tanto en Cartagena como en Málaga, al mismo precio que el del contrato anterior, siendo capaz de cumplir ambos. Como consecuencia de este éxito, a finales de febrero de 1640 planteó a este organismo hacerse cargo de vestir durante 10 años a todos los soldados de las levas realizadas en España, por un máximo de 10000 uniformes al año, a repartir entre los puertos de La Coruña, Cádiz, Málaga, Cartagena y Los Alfaques — por un precio comprendido entre los 120-I26 reales por unidad-, y en un régimen de monopolio, pues exigió que mientras estuviera en vigor ese acuerdo fuera la única instancia autorizada para proveer de uniformidad a los soldados. Finalmente, su propuesta fue rechazada, en gran medida por las dudas que suscitó en la Junta de Ejecución, órgano al que el monarca solicitó su parecer antes de autorizar la operación. Consulta de la Junta de Coroneles, Madrid, 15-4-1639, AGS, GYM, leg. I26I. Consulta de la Junta de Coroneles, Madrid, 24-2-1640, AGS, GYM, leg. I327. Consulta de la Junta de Ejecución, Madrid, 2-3-1640, AGS, GYM, leg. 1327.

132 Relación de las personas con quien están ajustadas levas por la Junta de Coroneles, s.I., s.f. (finales de 1640 principios de I64I), AGS, GYM, leg. 1273. 


\section{AGUSTÍN JIMÉNEZ MORENO}

ocurrió con el duque de Pastrana, con quien se acordó una leva de 200 hombres a presentar en Cartagena, a 25 ducados por unidad, si bien no se le entregó ninguna cantidad para iniciar la leva. En torno al mes de noviembre de 1640 ya había cumplido con la mitad del asiento, por lo que solicitó que le abonaran 2500 ducados, correspondientes al centenar de hombres que había entregado, o que se le dieran dos mercedes de hábito pues de lo contrario no podría cumplir el resto del servicio, como de hecho así ocurrió ${ }^{133}$.

Pero esta situación no solo ralentizó y paralizó los reclutamientos que ya estaban acordados, sino que impidió que fructificaran otros. A modo de ejemplo se puede mencionar el caso de D. Cristóbal de Zayas, quien estaba dispuesto a entregar 220 hombres vestidos en Cartagena a cambio de cuatro patentes de capitán, una merced de hábito y 6160 ducados (a 28 ducados por soldado); o el suscrito por D. Pedro Méndez por otros 200 ${ }^{134}$.

Cuadro 6. Leva de 3000 hombres para Italia realizada por la Junta de Coroneles (mediados I639-principios I64I). Fuentes: AGS, GYM, Legs. 1273, 1335, I336; AHNOB, Fernan Núñez, 70/I3.

\begin{tabular}{|c|c|c|c|}
\hline Reclutador & $\begin{array}{c}\text { Hombres a } \\
\text { entregar }\end{array}$ & $\begin{array}{c}\text { Hombres } \\
\text { entregados }\end{array}$ & $\begin{array}{l}\text { Porcentaje de } \\
\text { cumplimiento }\end{array}$ \\
\hline $\begin{array}{l}\text { Maestre de campo D. } \\
\text { Luis de Monsalve }\end{array}$ & 1000 & 727 । & $73 \%$ \\
\hline Capitán D. Juan de Leyva & 1000 & 1000 & $100 \%$ \\
\hline Vizconde de Valencina & 360 & $235^{2}$ & $65 \%$ \\
\hline Duque de Pastrana & 200 & 100 & $50 \%$ \\
\hline $\begin{array}{l}\text { D. Juna de Contefiesco y } \\
\text { D. Francisco Romero }\end{array}$ & $\begin{array}{r}200 \\
\text { (Vestidos) }\end{array}$ & 200 & $100 \%$ \\
\hline \multirow[t]{2}{*}{$\begin{array}{l}\text { Contador Diego de } \\
\text { Villanueva Ramírez }\end{array}$} & $\begin{array}{r}400 \\
\text { (Vestidos) }\end{array}$ & 237 & $59 \%$ \\
\hline & 3160 & 2499 & $79 \%$ \\
\hline
\end{tabular}

' Ver nota 3, cuadro 5.

${ }^{2}$ De ellos entregó 150 vestidos. En cuanto a los restantes 125 , acordó con la junta que fueran sustituidos por su equivalente económico, a razón de 26 ducados cada uno (en total 3250 ducados).

Me inclino a pensar que este debió ser el último reclutamiento en el que participó este organismo, pues las últimas noticias que he encontrado de su actividad datan del mes de abril de I64I, cuando la Junta de Ejecución protestó ante

133 Consulta de la Junta de Coroneles, Madrid, 3-II-I640, AGS, GYM, leg. I335. Relación de las personas con quien están ajustadas levas por la Junta de Coroneles, s.l., s.f. (finales de 1640 - principios de I64I), AGS, GYM, leg. 1273. Jiménez Moreno, 20I7b, pp. 434-436.

134 Consulta de la Junta de Ejecución, Madrid, 20-5-1640, AGS, GYM, leg. I328. Relación de las personas con quien están ajustadas levas por la Junta de Coroneles, s.l., s.f. (finales de 1640 - principios de I64I), AGS, GYM, leg. 1273. 


\section{LA ADMINISTRACIÓN REAL Y LA MOVILIZACIÓN DE LOS RECURSOS}

el monarca porque la de Coroneles se había apropiado de las cantidades reservadas para la compra de armas, exigiendo el reintegro de esos caudales inmediatamente ${ }^{135}$.

\section{CONCLUSIONES}

Pese a que la actividad de la Junta de Coroneles se prolongó durante poco más de cinco años, durante ese periodo de tiempo llevó a cabo una eficaz tarea reclutadora, que consiguió reunir, al menos, 30000 hombres - sin contar las levas efectuadas para la formación de los regimientos nobiliarios, que fue la razón que justificó su existencia-, lo que supone una media de 5000 soldados al año. Es cierto que no todos ellos acabaron finalmente en los frentes en los que combatía la monarquía española, pues había que tener en cuenta las deserciones, las muertes producidas por enfermedad - tanto en los puertos de embarque como en los trayectos hasta su lugar de destino-, o su apresamiento por el enemigo. Sin embargo, el éxito de esta entidad administrativa se debió a la conjunción de una serie de circunstancias que, si bien se identifican en otros momentos, durante los años finales de la década de los 30 del siglo XVII se dieron con mayor intensidad que nunca: unas necesidades militares en constante crecimiento, la ausencia de cualquier tipo de freno al empleo de mercedes y cargos de la oficialidad para gratificar a quienes reclutaban hombres para la Corona y, sobre todo, que en la primera línea política hubiera una persona, D. Gaspar de Guzmán, conde duque de Olivares, que respaldaba incondicionalmente esa línea de actuación.

No obstante, como se ha podido comprobar a lo largo de estas páginas, pese a que el sistema pareció funcionar relativamente bien durante unos años, pronto empezó a dar síntomas de agotamiento. Por una parte, esa política de uso indiscriminado de hábitos y patentes de la oficialidad no podía ser sostenida indefinidamente. En el caso de los primeros, hay testimonios que hablan de una saturación del mercado y un descenso de la cantidad o de los hombres a reclutar para obtener uno de esos honores, tanto por el exceso de oferta como por la competencia entre diferentes entidades reclutadoras - como la Junta de Hábitos, la Junta de Ejecución o el propio Consejo de Guerra-, que acarrearon una depreciación de estas mercedes. Además, el hecho de que no hubiera una dirección única en lo relativo al reclutamiento, generó numerosos choques y conflictos entre ellas. A ello hay que sumar que, desde aproximadamente la segunda mitad del año 1639, la Junta de Coroneles empezó a perder posiciones ante la Junta de Ejecución, liderada por el conde de Castrillo, quien poco a poco se convirtió en el principal organismo reclutador de la administración real.

\footnotetext{
${ }^{135}$ Consulta de la Junta de Coroneles, Madrid, 3-4-I64I, AGS, GYM, leg. 1258.
} 


\section{AGUSTÍN JIMÉNEZ MORENO}

Por otra parte, el uso masivo de patentes de la oficialidad amenazaba con crear un problema a las exhaustas finanzas reales, traducido en un considerable incremento del número de oficiales reformados, que en caso de prestar servicio activo percibirían el salario correspondiente a esa situación -el cual era más elevado que el de los soldados de plaza sencilla-. De la misma forma, si en ese momento optaban por finalizar su vinculación con la monarquía, muchos pasarían a formar parte del cada vez más amplio número de militares que pululaban por la Corte solicitando mercedes - con los problemas que ello ocasionaba, sobre todo de seguridad y orden público-. Todo ello se debía a que la designación como oficial, en la mayoría de los casos, se circunscribía al proceso de reclutamiento, siendo despedidos una vez se producía la entrega de los hombres en los puertos de embarque o, en último término, al llegar a los lugares de destino.

La falta de dinero fue, precisamente, el principal problema al que debió enfrentarse la Junta de Coroneles durante sus años de existencia, pues a pesar del importante papel jugado por hábitos y patentes a la hora de sacar adelante los reclutamientos, en muchos de los servicios pactados se necesitaban importantes sumas en metálico para conseguir que concluyeran con éxito. En cuanto a esta cuestión, el objetivo de la Corona era que la Junta de Coroneles fuera autosuficiente y desempeñara su actividad sin detraer fondos de la Real Hacienda, para lo cual se pusieron a su disposición una serie de arbitrios cuya venta, junto con el empleo de las mercedes honoríficas, debían bastar para financiar sus actividades. Pese a que en el plano teórico este esquema estaba bien planteado, la realidad se encargó de poner las cosas en su sitio. Así, las levas efectuadas por asentistas, cuando no se costeaban con hábitos y/o empleos de la oficialidad, eran caras. $Y$ sin una fuente de ingresos regular sería prácticamente imposible finalizarlas con éxito. Eso fue lo que finalmente ocurrió, pues las cantidades obtenidas por la venta de esos medios, o no generaron los ingresos esperados o no entraron en la bolsa de este organismo con la rapidez y la regularidad necesaria.

Cuadro 7. Efectivos reclutados por la Junta de Coroneles entre 1636 y 1640

\begin{tabular}{l|r|l|l}
\hline \hline \multicolumn{1}{c|}{ Año } & $\begin{array}{r}\text { Número de hombres } \\
\text { entregados }\end{array}$ & $\begin{array}{c}\text { Puertos de } \\
\text { embarque }\end{array}$ & \multicolumn{1}{c}{ Destino } \\
\hline 1636 & $\begin{array}{r}3000 \\
\text { (Aproximadamente) }\end{array}$ & La Coruña & Ejército de Flandes \\
\hline 1637 & 4126 & La Coruña y Cádiz & Ejército de Flandes \\
\hline 1638 & 6500 & $\begin{array}{l}\text { Cartagena, Cádiz y } \\
\text { Los Alfaques }\end{array}$ & Ejército de Milán y Armada \\
\hline 1639 & $14000^{\prime}$ & $\begin{array}{l}\text { Cádiz, Málaga, } \\
\text { Cartagena y La } \\
\text { Coruña }\end{array}$ & $\begin{array}{l}\text { Ejército de Flandes, Ejército de } \\
\text { norteafricanos }\end{array}$ \\
\hline I640 & 2500 & Málaga y Cartagena & Ejército de Milán \\
\hline \hline
\end{tabular}




\section{LA ADMINISTRACIÓN REAL Y LA MOVILIZACIÓN DE LOS RECURSOS}

Otro de los hechos que llama la atención es que a pesar de la delicada coyuntura por la que atravesaba la Real Hacienda, con multitud de compromisos a los que atender, al tiempo que la demanda de soldados para los ejércitos era más alta que nunca, la administración real no sucumbió a la tentación de aceptar prácticamente cualquier oferta, frenando las aspiraciones de algunos particulares de aprovecharse de la situación para solicitar unas mercedes que en otras circunstancias no se habrían atrevido a pedir, o exigir unos premios muy por encima del servicio a realizar. Cuando se produjo esa circunstancia, la Corona rechazó sin contemplación las ofertas presentadas ${ }^{136}$, lo cual indicaría que a pesar de lo perentorio de la situación, todo tenía un límite.

También merecería una mayor reflexión, así como investigaciones de mayor calado, el modo en que los reclutamientos proyectados por la Junta de Coroneles pasaban de la teoría a la práctica. Lo cierto es que sabemos muy poco sobre el modo en que este organismo contactaba con los particulares interesados en levantar hombres para ella, o si por el contrario eran estos quienes lo hacían. En virtud de la poca información que he podido recopilar sobre esta cuestión, debieron producirse las dos situaciones, pues en algún caso era la propia Corona quien sugería ciertos nombres - sobre todo de aristócratas-, y en otros supuestos, sobre todo reclutadores profesionales, e individuos interesados en obtener alguna merced, eran estos quienes presentaban sus ofertas.

Para finalizar, considero que el balance final sobre Junta de Coroneles debe ser positivo, pues gracias a ella la Corona accedió a unos recursos - humanos en este caso- que de otra forma no hubiera conseguido, o le habría sido mucho más dificultoso acceder a ellos. En todo ello tuvo un jugó un papel clave la negociación y el acuerdo, aunque también la coacción, como hemos visto en el caso de los nobles a quienes se reclamó la devolución de las alcabalas de algunas de

136 Como por ejemplo ocurrió con D. Luis de Peralta, gentilhombre de la boca, que ofreció aprestar dos compañías de caballos (200 hombres en total), entregados en Málaga a cambio del corregimiento de Antequera, así como la futura sucesión del de Toledo o Murcia. Consulta de la Junta de las Coronelías, Madrid, 17. 4-1637, AGS, GYM, leg. I 185. El capitán D. José Luis Tello de Vera también vio rechazado su ofrecimiento de levar en Sevilla un centenar de hombres, corriendo con los gastos hasta su entrega en el presidio de Cádiz, a cambio de que se le hiciera merced de la futura sucesión del empleo de corregidor de Zacatecas -en el virreinato de Nueva España, y el principal centro productor de plata de esa jurisdicción-, cuando concluyera el mandato de la persona que lo estaba sirviendo. Consulta de la Junta de Coronelías, Madrid, 27 5-1637, AGS, GYM, leg. I 186. Tampoco se aceptó la oferta del capitán D. Juan de Isásaga y Mújica, que solicitó la futura sucesión del puesto de gobernador de Yucatán, así como un hábito para su hijo, por servir personalmente en Guipúzcoa junto con 9 soldados, vestidos, armados y pagados a su costa. Consulta de la Junte de Coroneles, Madrid, 28-5-1639, AGS, GYM, leg. I26I. Algo parecido sucedió con D. Ignacio de Santander, quien en mayo de 1639 solicitó, a cambio de levantar 50 hombres entregados en Cádiz, permiso para adehesar - cercar y convertir en tierra de pastos-, permiso para imponer censos por 3000 ducados, y dos mercedes de hábito - una para él y otra para su hijo-. Consulta de la Junta de Coroneles, Madrid, 28-51639, AGS, GYM, leg. I26I. 


\section{AGUSTÍN JIMÉNEZ MORENO}

sus localidades. Pero incluso en esos casos, cuando ambas instancias llegaron a un acuerdo, la administración real fue más que generosa con ellos, facilitándoles la tarea todo lo posible.

\section{BIBLIOGRAFÍA}

Alcalá-Zamora y Queipo de Llano, José, España, Flandes y el Mar del Norte (I6/8-1639). La última ofensiva de los Austrias madrileños, Barcelona, Planeta, 1975.

Alloza Aparicio, Ángel, «La Junta del Almirantazgo y la lucha contra el contrabando, I625-I643», Espacio, Tiempo y Forma, Serie IV. Historia Moderna, 16, 2003, pp. 217-254.

Alloza Aparicio, Ángel, «Guerra económica y comercio europeo en España, I624-1674. Las grandes represalias y la lucha contra el contrabando», Hispania, 219, 2005, pp. 227-280.

Alloza Aparicio, Ángel y Juan Carlos Zofío Llorente, «La trepidante carrera de sir Benjamin Wright. Comerciante, factor y asentista de Felipe IV», Hispania, 245, 2013, pp. 673-702.

Álvarez y Baena, José Antonio, Hijos de Madrid, Madrid, Oficina de Benito Cano, I789-179I, 4 vols.

Andújar Castillo, Francisco, El sonido del dinero. Monarquía, ejército y venalidad en la España del siglo XVIII, Madrid, Marcial Pons, 2004.

Andújar Castillo, Francisco, «Empresarios de la guerra y asentistas de soldados en el siglo XVII», en Guerra y sociedad en la Monarquía Hispánica. Política, estrategia y cultura en la Europa Moderna (I500-I700), ed. Enrique García Hernán y Davide Maffi, Madrid, Fundación Mapfre-Ediciones del Laberinto-CISC, 2006, II, pp. 375-394.

Andújar Castillo, Francisco, «Los generales y almirantes de la Carrera de Indias en el último tercio del siglo XVII. Préstamos y venalidad», en Andalucía y el mundo atlántico moderno. Agentes y escenarios, ed. Juan José Iglesias Rodríguez y José Jaime García Bernal, Madrid, Sílex, 2016, pp. 265-287.

Andújar Castillo, Francisco, «Marinos o mercaderes: sobre los mandos de las armadas de la Carrera de Indias en el reinado de Carlos II», en Andalucía en el mundo atlántico moderno. Ciudades y redes, ed. Juan José Iglesias Rodríguez, José Jaime García Bernal y José Manuel Díaz Blanco, Madrid, Sílex, 2018, pp. 239 261 .

Baltar Rodríguez, Juan Francisco, Las juntas de gobierno en la Monarquía Hispánica (siglos XVI-XVII), Madrid, Centro de Estudios Políticos y Constitucionales, 1998.

Baltar Rodríguez, Juan Francisco, «Las negociaciones del Consejo de Aragón en el siglo XVII», Anuario de Historia del Derecho Español, 7I, 200I, pp. 267-316.

Calvo Poyato, José, «Venta de baldíos y tensión social en Andalucía a mediados del siglo XVII», Agricultura y Sociedad, 55, 1990, pp. 95-124.

Díaz Blanco, José Manuel, «Sobre las armadas de Indias: la práctica del beneficio y la crisis de la avería (I660I700)», Gladius, 35, 20I5, pp. II7-I38.

Domínguez Nafría, Juan Carlos, El Real y Supremo Consejo de Guerra, Madrid, Centro de Estudios Políticos y Constitucionales, 200I.

Domínguez Ortiz, Antonio, Política y hacienda de Felipe IV, Madrid, Editorial de Derecho Financiero, 1960.

Domínguez Ortiz, Antonio, Las clases privilegiadas en el Antiguo Régimen, Madrid, Istmo, 1973.

Domínguez Ortiz, Antonio, «La comisión de D. Luis Gudiel para la venta de baldíos de Andalucía», en Actas del Congreso de Historia Rural. Siglos XV-XIX, Madrid, Casa de Velázquez-Universidad Complutense, 1984, pp. 5 II-522.

Elliott, John H., La rebelión de los catalanes (1598-I640), Madrid, Siglo XXI, 1977.

Elliott, John H., El Conde Duque de Olivares. El político de una época en decadencia, Barcelona, Crítica, $1990\left(I^{\mathrm{a}}\right.$ edición en inglés, New Haven-London, Yale University Press, 1986).

Elliott, John H., José Francisco De la Peña y Fernando Negredo del Cerro, Memoriales y cartas del conde duque de Olivares, Vol. I, Política interior (1621-1643), Madrid, Marcial Pons-Centro de Estudios Europa Hispánica, 2013

Escudero, José Antonio, Los hombres de la monarquía universal, Madrid, Real Academia de la Historia, 201 I.

Fayard, Janine, Los miembros del Consejo de Castilla (I62 I-I 746), Madrid, Siglo XXI, 1982.

Fernández Álvarez, Manuel, D. Gonzalo Fernández de Córdoba y la guerra de Sucesión de Mantua y del Monferrato (1627-1629), Madrid, CSIC, 1955. 


\section{LA ADMINISTRACIÓN REAL Y LA MOVILIZACIÓN DE LOS RECURSOS}

Fernández Duro, Cesáreo, Armada española desde la unión de los Reinos de Castilla y de Aragón, Madrid, Sucesores de Rivadeneyra, I895-1903.

Gascón de Torquemada, Jerónimo, Gaceta y nuevas de la Corte de España desde el año 1600 en adelante, ed. Alfonso de Ceballos-Escalera y Gila, Madrid, Real Academia Matritense de Heráldica y Genealogía, 1991.

Gelabert González, Juan Eloy, Castilla convulsa, I63/-1652, Madrid, Marcial Pons, 200 I.

Gil Martínez, Francisco, «"Que todo es regalía de Su Majestad”. La junta para la venta de las escribanías de cámara de la Comisión de Millones (I636)», Chronica Nova, 39, 2013, pp. 323-334.

Gil Martínez, Francisco, «Las hechuras del Conde Duque de Olivares. La alta administración de la monarquía desde el análisis de redes», Cuadernos de Historia Moderna, 40, 20I5, pp. 63-88.

Gil Martínez, Francisco, La Junta de Vestir la Casa (I 636- / 643). Juntas, financiación de la Corte y venalidad, Madrid, Polifemo, 2017.

Gil Martínez, Francisco, «¿A qué precio? Los ministros especializados en la venalidad durante el periodo de Olivares», e-Spania, 33, 2019

Gómez Vozmediano, Miguel Francisco, «Duelos y duelistas en la Corte (de Carlos II a Carlos III). Entre la práctica social y la condena moral», en La cultura de la espada. De honor, duelos y otros lances, ed. Raquel Sánchez y José Antonio Guillén Berrendero, Madrid, Dykinson, 2019, pp. 95-121.

Goodman, David, El poderío naval español. Historia de la Armada española del siglo XVII, Barcelona, Península, $200 \mathrm{I}$

Guillén Berrendero, José Antonio, «Duelo, honor y nobleza en la Edad Moderna. Un tema y varias interpretaciones», en La cultura de la espada. De honor, duelos y otros lances, ed. Raquel Sánchez y José Antonio Guillén Berrendero, Madrid, Dykinson, 2019, pp. 43-61.

Jago, Charles, «The Influence of Debt on the Relations between Crown and Aristocracy in Seventeenth Century Castile», The Economic History Review, 36, 1973, pp. 218-236.

Jago, Charles, «The Crisis of the Aristocracy in Seventeenth-Century Castile», Past and Present, 84, 1979, PP. 60-90.

Jiménez Estrella, Antonio, «El reclutamiento en la primera mitad del siglo XVII y sus posibilidades venales» en $E$ poder del dinero. Ventas de cargos y honores en el Antiguo Régimen, ed. Francisco Andújar Castillo y María del Mar Felices de la Fuente, Madrid, Biblioteca Nueva, 201 I, pp. 169-190.

jiménez Estrella, Antonio, «Servir al rey, recibir mercedes: asentistas militares y reclutadores portugueses al servicio de Felipe IV antes de la Guerra de Restauración» en Cargos e oficios nas monarquias ibéricas: provimento, controlo e venalidade (séculos XVII e XVIII), ed. Roberta Stumpf y Nandini Chaturvedula, Lisboa, Centro de Historia de Além-Mar, 2012a, pp. 239-266.

Jiménez Estrella, Antonio, «Mérito, calidad y experiencia: criterios volubles en la provisión de cargos militares bajo los Austrias», en Oficiales reales. Los ministros de la Monarquía Católica (siglos XVI-XVII), coords. Juan Francisco Pardo Molero y Manuel Lomas Cortés, Valencia, Universitat de Valencia, 20I2b, Pp. 24I264.

Jiménez Estrella, Antonio, «“No ha interesado otra cosa más que el servir a Vuestra Majestad”. Las levas del duque de Pastrana durante el valimiento de Olivares: servicio, mercedes y beneficio» en Gobernar y reformar la monarquía: los agentes políticos y administrativos en España y América. Siglos XVI-XIX, ed. Michel Bertrand, Francisco Andújar Castillo y Thomas Glesener, Valencia, Albatros, 2017, pp. I5I-169.

Jiménez Moreno, Agustín, Nobleza, guerra y servicio a la Corona. Los caballeros de hábito en el siglo XVII, Madrid, Universidad Complutense, 20II.

Jiménez Moreno, Agustín, Monarquía, aristocracia y reclutamiento en el siglo XVII. La formación de regimientos nobiliarios durante el ministerio del Conde Duque de Olivares (I 632-I643), Valladolid, Universidad de Valladolid, 2018.

Jover Zamora, José María, 1635. Historia de una polémica y semblanza de una generación. Madrid, CSIC, 2003.

Lanza García, Ramón, «El donativo de las guerras de Italia (1629): estudio del caso del arzobispado de Toledo y la provincia de Guadalajara», Obradoiro de Historia Moderna, 19, 2010, pp. I25-159.

Lanza García, Ramón, «La enajenación de bienes comunales en la Castilla del siglo XVII: naturaleza y alcance de un expediente fiscalı, en Campo y campesinos en la España Moderna. Culturas políticas en el mundo hispano, León, FEHM-Universidad de León, 2012, II, Pp. 373-388.

Lohmann Villena, Guillermo, Los americanos en las órdenes nobiliarias, Madrid, CSIC, 1993

López Belinchón, Bernardo José, «Sacar la sustancia al reino. Comercio, contrabando y conversos portugueses, I62I, I640», Hispania, 209, 200I, Pp. 1017-1050. 


\section{AGUSTÍN JIMÉNEZ MORENO}

Mackay, Ruth, The Limits of Royal Authority. Resistance and Obedience in Seventeenth-Century Castile, Cambridge, Cambridge University Press, 1999.

Martínez Hernández, Santiago, «"Por estar tan acostumbrados a cometer semejantes excesos”: una aproximación a la violencia nobiliaria en la corte española del Seiscientos», en Nobilitas. Estudios sobre la nobleza y lo nobiliario en la Europa Moderna, dir. Juan Hernández Franco, José Antonio Guillén Berrendero y Santiago Martínez Hernández, Madrid, Ediciones Doce Calles-Fundación Cultural de la Nobleza Española-Fundación Séneca-Ediciones de la Universidad de Murcia, 2014, pp. 255-297.

Montojo Montojo, Vicente, El Siglo de Oro en Cartagena (I480-1640). Evolución económica y social de una ciudad portuaria del Sureste español y su comarca, Murcia, Ayuntamiento de Murcia-Real Academia Alfonso X el Sabio-Universidad de Murcia, 1993.

Ortego Gil, Pedro, «La pena de vergüenza pública (siglos XVI-XVIII). Teoría legal castellana y práctica judicial gallega», Anuario de Derecho Penal y Ciencias Penales, 5I, 1998, pp. 153-204.

Parker, Geoffrey (ed.), La Guerra de los Treinta Años, Madrid, Antonio Machado Libros, 2003.

Parrott, David, «The Causes of the Franco-Spanish War of I635-1659», en The Origins of War in Early Modern Europe, ed. Jeremy Black, Edinburgh, Donald Publishers, 1987, pp. 72-III.

Parrott, David, «The Mantuan Succession, I627-1631: A Sovereignty Dispute in Early Modern Europe», English Historical Review, I I2, 1997, pp. 20-65.

Parrott, David, Richelieu's Army. War, Government and Society in France, 1624-1642, Cambridge, Cambridge University Press, 200I.

Parrott, David, The Business of War. Military Enterprise and Military Revolution in Early Modern Europe, Cambridge, Cambridge University Press, 2012.

Pérez de Tudela y Bueso, Juan, Sobre la defensa hispana del Brasil contra los holandeses ( / 62 I- /640), Madrid, Real Academia de la Historia, 1974.

Ramos, Antonio, Aparato para la corrección y adición de la obra que publicó en 1769 el Dr. D. José Berní y Catalá con el título Creacion, antiguedad, y privilegios de los Títulos de Castilla, Málaga, Oficina del Impresor de la Dignidad Episcopal y de la Santa Iglesia, 1777.

Ródenas Vilar, Rafael, La política europea de España durante la Guerra de los Treinta Años (I624-1630), Madrid, CSIC, 1967.

Rodríguez Hernández, Antonio José, «El reclutamiento de españoles para el Ejército de Flandes en la segunda mitad del siglo XVIII), en Guerra y sociedad en la Monarquía Hispánica. Política, estrategia y cultura en la Europa Moderna (I 500-I 700), ed. Enrique García Hernán y Davide Maffi, Madrid, Fundación MapfreEdiciones del Laberinto-CSIC, 2006, II, pp. 395-434.

Rodríguez Hernández, Antonio José, «Patentes por soldados: reclutamiento y venalidad en el ejército durante la segunda mitad del siglo XVII», Chronica Nova, 33, 2007a, pp. 37-56.

Rodríguez Hernández, Antonio José, «De Galicia a Flandes: reclutamientos y servicios de soldados gallegos en el ejército de Flandes (1648- I700)», Obradoiro de Historia Moderna, 2007b, pp. 2| 3-25I.

Rodríguez Hernández, Antonio José, Los tambores de Marte. El reclutamiento en Castilla durante la segunda mitad del siglo XVII (I648-I 700), Valladolid, Universidad de Valladolid-Ediciones Castilla, 20I I.

Rodríguez Hernández, Antonio José, «Asentistas, intermediarios y mercaderes de hombres: el caso de Francisco de Torres Castejón (1648)», en Actas de la XI Reunión Científica de la FEHM, ed. Antonio Jiménez Estrella y Julián José Lozano Navarro, Granada, Universidad de Granada, 20 I2, II, pp. II I94-I 205.

Rodríguez Hernández, Antonio José, «Los judeoconversos y el negocio de la guerra: la leva de Manuel Cortizos por vía de factoría (I648)», Hispania, 253, 2016, pp. 473-5I0.

Rodríguez Hernández, Antonio José, «El primer modelo de reclutamiento forzoso en España durante la Edad Moderna: las levas para los presidios (I634-I642)», Millars, 43, 20I7, pp. I5I-I87.

Sánchez Durán, Álvaro, «Gobierno y redes clientelares en la Monarquía Hispánica de Felipe IV: el protonotario Jerónimo de Villanueva y la Corona de Aragón (I626-I643)», Pedralbes, 36, 2016, pp. 249-299.

Sánchez González, Dolores del Mar, «La Junta de Ejecución: el órgano rector de los destinos de la monarquía», en Estudios sobre ejército, política y derecho en España (siglos XII-XX), ed. Javier Alvarado Planas y Regina M. Pérez Marcos, Madrid, Polifemo, 1996, Pp. I31-150.

Sanz Camañes, Porfirio, Diplomacia hispano-inglesa. Razón de estado y relaciones de poder durante la Guerra de los Treinta Años (16 / 8-1648), Cuenca, Universidad de Castilla-La Mancha, 2002.

Stradling, Robert A., «Olivares and the Origins of the Franco-Spanish War, 1627-|635», The English Historical Review, 101, 1986, pp. 68-94. 


\section{LA ADMINISTRACIÓN REAL Y LA MOVILIZACIÓN DE LOS RECURSOS}

Stradling, Robert A., «Prelude to Disaster: The Precipitation of the War of the Mantuan Sucession, I627-1629», The Historical Review, 33, 1990, pp. 769-785.

Stradling, Robert A., «Los dos grandes luminares de la tierra: España y Francia en la política de Olivares», en Lo España del Conde Duque de Olivares, coords. John H. Elliott y Ángel García Sanz, Valladolid, Universidad de Valladolid, 1990, pp. 131-160

Stradling, Robert A., La Armada de Flandes. Política naval y guerra española, 1558-/658, Madrid, Cátedra, 1992.

Taylor, Harland, «Trade, neutrality and the English Road, I630-I648», The Economic History Review, 25, 1975, Pp. 236-260.

Thompson, Irving A., Guerra y decadencia. Gobierno y administración en la España de los Austrias, I560-1620, Barcelona, Crítica, 1981.

Urbina y Ceballos-Escalera, Julio de, Lances entre caballeros, Madrid, Sucesores de Rivadeneyra, 1900.

Valladares Ramírez, Rafael, «Las dos guerras de Pernambuco: la armada del conde da Torre y la crisis del Portugal hispánico (I638-I64I)», en El desafio holandés al dominio ibérico en Brasil en el siglo XVII, ed. José Manuel Santos Pérez y George Félix Cabral de Souza, Salamanca, Universidad de Salamanca, 2006, pp. 33-66.

Vallejo García-Hevia, José María, «El correo mayor de las Indias (15|4-|768)», en Derecho y administración pública en las Indias Hispánicas, ed. Feliciano Barrios Pintado, Cuenca, Ediciones de la Universidad de Castilla-La Mancha, 2002, II, pp. I785-I8I0.

Vermeir, René, En estado de guerra. Felipe IV y Flandes, I629-I648, Córdoba, Universidad de Córdoba, 2006.

Vila Villar, Enriqueta, Los Corzo y los Mañara: tipos y arquetipos del mercader con América, Sevilla, CSIC, I99I.

Wilson, Peter H., La Guerra de los Treinta Años. Una tragedia europea (I 630-I 648), Madrid, Desperta Ferro, 2018.

Yun Casalilla, Bartolomé, «La situación económica de la aristocracia castellana durante los reinados de Felipe III y Felipe IV», en La España del Conde Duque de Olivares, ed. John H. Elliott y Ángel García Sanz, Valladolid, Universidad de Valladolid, 1990, Pp. 519-55I. 